\title{
Experimental Simulation Study on Water Migration and Methane Depressurizing Desorption Based on Nuclear Magnetic Resonance Technology: A Case Study of Middle-Rank Coals from the Panguan Syncline in the Western Guizhou Region
}

\author{
Junjian Zhang ${ }^{1,2,3}$, Chongtao Wei ${ }^{1,2^{\star}}$, Veerle Vandeginste ${ }^{3}$, Wei Jü , Zengyuan Qin ${ }^{1,2}$, Fangkai \\ Quan $^{1,2}$, Landry Soh Tamehe ${ }^{1,5}$
}

${ }^{1}$ Key Laboratory of Coalbed Methane Resource \& Reservoir Formation Process, Ministry of Education, China University of Mining and Technology, Xuzhou 221008, China

${ }^{2}$ School of Resources and Earth Science, China University of Mining and Technology, Xuzhou 221116, China

${ }^{3}$ GeoEnergy Research Centre and School of Chemistry, University of Nottingham, University Park, NG7 2RD, Nottingham, UK

${ }^{4}$ Nottingham Geospatial Institute, University of Nottingham, Jubilee Campus, NG7 2TU, Nottingham, UK

${ }^{5}$ Department of Earth Sciences, University of Yaoundé I, P.O. Box 3412 Messa, Yaounde,Cameroon

\begin{abstract}
Water migration and methane desorption characteristics directly affect the performance of coalbed methane wells. In this paper, migration and desorption variability of methane and water in adsorption pores, seepage pores, and fractures were studied by laboratory simulation using an improved nuclear magnetic resonance displacement device. The results are as follows: Both adsorbed and bulk methane decreased logarithmically with the increase of the desorption time under the condition of one-stop desorption. The desorption process can be divided into the early rapid decline stage and the later slow desorption stage. In comparison to one-stop desorption, step-by-step depressurizing desorption can effectively increase the loss rate of the methane amount. For the two desorption modes, the variation rate of bulk methane is much higher than that of adsorbed methane at the same desorption time. The sensitivity of large pores to displacement nitrogen pressure is stronger than that of adsorption pores. In the process of methane displacement by water, the variation of bulk methane is larger than that of adsorbed methane, whereas the variation of adsorbed methane is more sensitive to injecting water pressure than that of bulk methane. The above results indicate that the quantity of water injected into the coal seam and the water drainage rate have an effect on methane desorption in the adsorption pore. Therefore, the parameters of depressurization value should be fully considered in the drainage system setting of coalbed methane wells.
\end{abstract}

\section{Introduction}

Coalbed methane (CBM) is one of the most important unconventional resources in China. The accumulation mechanism of coal reservoirs and the dynamic variation of physical properties during the process of drainage have attracted great attention.(1-6) However, there are relatively few studies on gas and water migration in coal reservoirs. The pressure of the coal reservoir gradually decreases to the critical desorption pressure during the drainage of CBM, which leads to methane in the adsorption pore to desorb and migrate from the matrix to the fracture by way of diffusion. Then, methane migrates and produces through fractures to the wellbore driven by the production pressure differential. Therefore, the essence of CBM drainage is the process of migration and interaction between water and methane under different pressure and temperature conditions in coal reservoirs. Methane and other gas adsorption capacities of a coal reservoir are commonly studied by an isothermal adsorption experiment(7-11) and molecular simulation methods.(12-14) Moreover, the influence of free water in a coal reservoir on methane adsorption and desorption was studied.(15-20)From the above results, it can be concluded that the adsorption capacity of methane decreases with the increase of the free water content, and the effect of free water on methane adsorption is less than that of carbon dioxide. Moreover, invasion water mainly displaces adsorbed methane in nanopores of coal and, thus, enhances the free gas content, in which the displacement mechanism can be attributed to the capillary effect and preferential flow in a coating mode. 
To achieve a separate description of adsorbed and bulk methane variation, Yao et al.(21) established a set of isothermal adsorption experimental devices using low-field nuclear magnetic resonance (LFNMR) technology. The adsorption volume decided by the devices is in good agreement with the traditional volumetric method, in which the absolute deviation between the experimental data of two methods is within $+2 \mathrm{~m}^{3} / \mathrm{t}$. This result indicates that LF-NMR can achieve an evaluation on the adsorbed methane capacity of coal. Liu et al.(22) first evaluated the exchange of adsorbed, nonadsorbed, and free-phase methane in shale reservoirs during the injection of carbon dioxide using LFNMR technology.

The above results provide a theoretical basis for studying the characteristics of multiphase methane adsorption and migration in unconventional reservoirs. Then, Liu et al. and Yao et al. obtained the absolute adsorption isotherms of methane and divided the transverse relaxation time $\left(T_{2}\right)$ value into adsorbed and free methane in shale by LF-NMR technology, respectively. $(23,24)$ Moreover, some researchers studied the effect of different gases (carbon dioxide and nitrogen) on methane adsorption and desorption by studying the variation of $T_{2}$ spectra of multiphase methane, including adsorbed, bulk, and free methane,(25-27) and found that carbon dioxide can replace adsorbed methane from the pore surface, decreasing the adsorbed molar amount of it, and then replaced methane seems to only become a free state in the pore center and hardly escape from the organic pores.

Moreover, Liu et al.(28) simulated the one-stop desorption process of anthracite coal samples from the Qinshui basin (China) using NMR technology. This result indicates that adsorption and desorption curves of dry coal samples vary logarithmically with time, and the moisture content has a significant effect on methane adsorption and desorption.

In addition, free water inside coal reservoirs often takes part in actual CBM recovery; therefore, this factor must be considered to achieve an accurate simulation of the CBM drainage process. Some researchers characterize the stress sensitivity of the pore-fracture system by studying the variation of free water in the pore of different sizes using LF-NMR technology, which indicated that the compressibility decreases with the increase of the coal rank, and there exists a good logarithmic relationship between the value and effective stress.(29-31) Meanwhile, the migration of nitrogen, carbon dioxide, and movable water in pore-fracture systems using a $T_{2}$ spectrum was also studied,(32-34) which indicated that those gases can effectively reduce the wettability of water in the coal surface and adsorbed water can be changed to free water. Li et al.(35) studied the variation of the water content after nitrogen flooding, indicating that the retained water content of a sample with connected apertures is discharged effectively under nitrogen driving, while a sample that lacks connected apertures remains high in retained water content.

In conclusion, some achievements have been obtained in the application of NMR technology to study gas and water migration in a coal reservoir, but there are still shortcomings in terms of the experimental conditions. These are manifested in the limitation of the instrument that measures the desorption process of samples and the one-stop desorption process setting the desorption pressure to atmospheric pressure $(0.1 \mathrm{MPa})$. It is difficult to objectively represent the step-by-step depressurizing in the process of CBM drainage; therefore, the results are difficult to apply directly to an actual CBM recovery project. Moreover, methane desorption and movable water migration characteristics in the one single coal sample also need further study.

In this paper, the existing nuclear magnetic displacement device and testing method were modified by adding a back-pressure valve to control desorption pressure artificially. A set of physical simulation experiments reflecting desorption of CBM during the process of pressure reduction has been conducted. The following goals were tried to achieve: Migration characteristics of free water in adsorption and seepage pores as well as fractures will be studied. Then, dynamic variation of adsorbed and bulk methane are going to be quantitatively described. Then, desorption variation of absorbed and bulk methane under different desorption modes will be analyzed. Finally, heavy water is used as a medium to describe the methane displacement process in detail.

\section{Sample and Experimental Technologies}

\subsection{Geological Setting and Sample Collection}

The sampling area, involving two coal mines of the Tucheng area, coal mines of SJ and $X Z$, is located in western Guizhou, which is an important coal production base and where abundant CBM resources occur; its CBM resource is approximately between 2.20 and $2.75 \times 10^{12} \mathrm{~m}^{3}(36)$ (Figure 1). Coal bearing strata are the late Permian Longtan Formation and Changxing Formation, which belong to a delta-tidal-lagoon sedimentary system, whereby the Tucheng syncline controls the general distribution of coal seams. Maturation of coal seams gradually increase with the increase of their burial depth, and the maximum vitrinite reflectance $\left(R_{\circ, \max }\right)$ is between 0.5 and $2.5 \%$. Two fresh coal 
samples (approximately $15 \times 15 \times 15 \mathrm{~cm}^{3}$ ) were collected. Sampling location and basic parameters of the two samples are presented in Figure 1 and Table_1, respectively.

Table 1. Basic Information of Coal Samples SJ and XZ Collected from the Target Area

\begin{tabular}{|c|c|c|c|c|c|c|c|c|c|c|}
\hline \multirow{2}{*}{ Sample } & \multirow{2}{*}{$R_{\mathrm{o}, \max }(\%)$} & \multirow{2}{*}{$\begin{array}{c}\text { Depth } \\
\text { (m) }\end{array}$} & \multirow{2}{*}{$\begin{array}{l}\text { Coal seam } \\
\text { Number }\end{array}$} & \multirow{2}{*}{$\begin{array}{l}\text { Coal } \\
\text { Mine }\end{array}$} & \multicolumn{4}{|c|}{ Proximate (wt,\%) } & \multirow{2}{*}{$\begin{array}{c}\text { Porosity } \\
(\%)\end{array}$} & \multirow{2}{*}{$\begin{array}{c}\text { Permeabilit } \\
\mathrm{y}(\mathrm{mD})\end{array}$} \\
\hline & & & & & $M_{\mathrm{ad}}$ & $A_{\text {ad }}$ & $V_{\text {daf }}$ & $F C_{\text {ad }}$ & & \\
\hline SJ & 1.32 & 780 & $12 \#$ & Shanjiao & 0.88 & 25.04 & 27.71 & 54.19 & 2.07 & 0.47 \\
\hline $\mathrm{XZ}$ & 2.20 & 920 & $7 \#$ & Xi Zhai & 1.94 & 10.67 & 12.68 & 78.00 & 7.05 & 0.88 \\
\hline
\end{tabular}

$R_{\text {o,max }}$ maximum vitrinite reflectance (\%); Mad, moisture content on an air-dried basis (\%); $A_{\text {ad, }}$ airdried ash yield (\%); $V_{\text {daf, }}$ volatile yield on an air-dried basis (\%); and $F C_{\text {ad, }}$ fixed carbon content (\%).

Figure 1

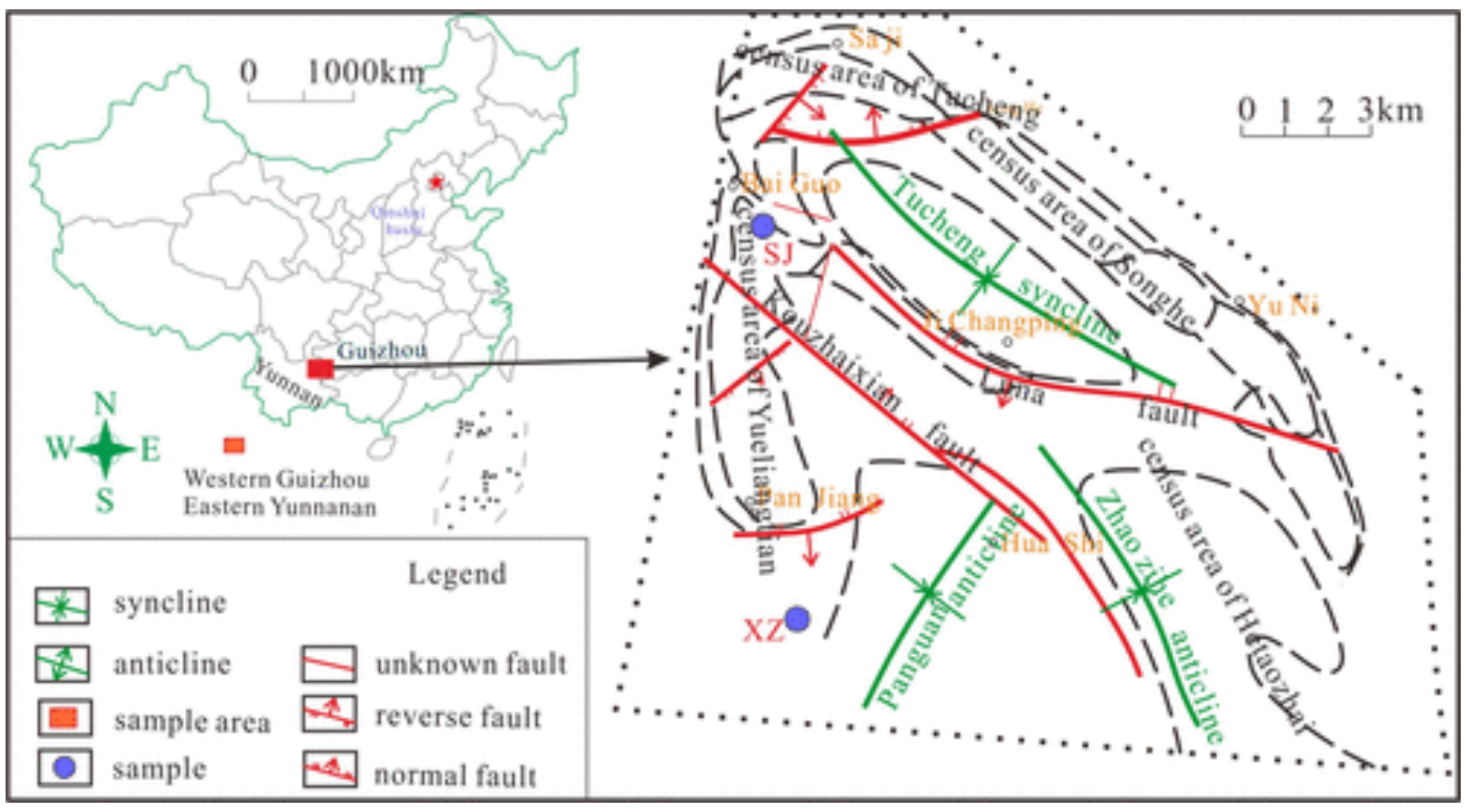

Figure 1. Distribution of the sampling locations and tectonic sketch map of the study area.

\subsection{Experimental Device}

The NMR simulation experiment was conducted by an improved high-temperature and high-pressure (HTHP) displacement instrument (MacroMR12-150H-1 tester). The maximum length of the sample is $150 \mathrm{~mm}$. The temperature of the magnet is controlled by a nonlinear precise thermostat with a temperature range of 25 and $35^{\circ} \mathrm{C}$. ${ }^{1} \mathrm{H}$ resonance frequency ranges from 1 to $30 \mathrm{MHz}$. The maximum gas pressure and confining pressure of the holder are 20 and $40 \mathrm{MPa}$, respectively.

The device consists of six subsystems (Figure 2). Among them, subsystem 1 is used to display NMR signal, pressure, and temperature data. Subsystems 2 and 3 are displacement devices used to provide gas (methane and nitrogen) and water, respectively. Subsystem 4 is the key part of the whole system. It consists of a holder and a NMR device. The latter can output a continuous $T_{2}$ signal.

Subsystem 5 is the pressurized portion of the instrument that can provide a continuous variation of confining pressure. Subsystem 6 is an outlet pressure controlling device, and the outlet pressure can be varied by a valve (back-pressure valve). This section is a specific modification for the tests conducted for this paper. The system can achieve a successive setting of the outlet pressure that can conduct the step-by-step depressurizing process or simulate the CBM drainage process. 


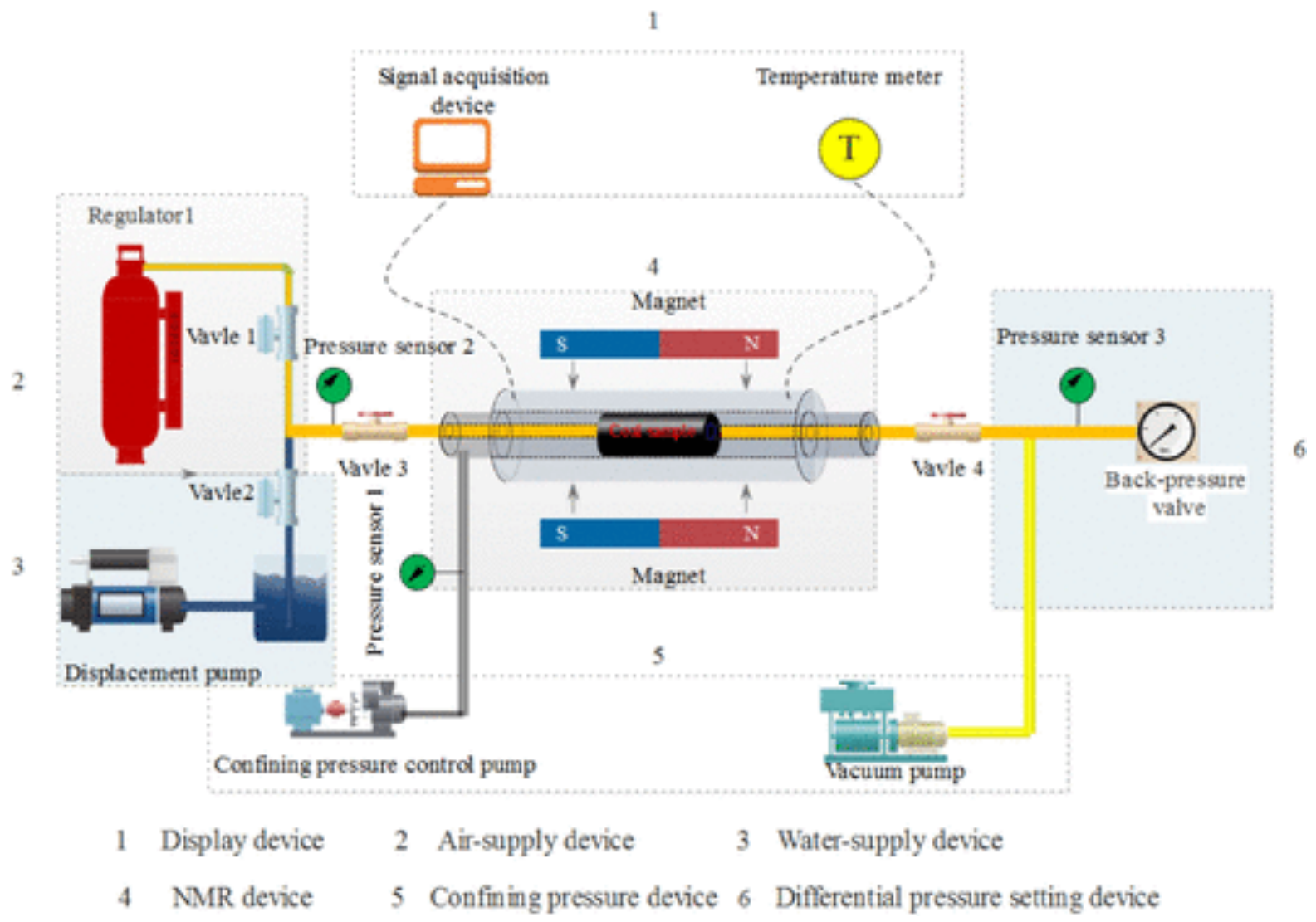

Figure 2. Schematic of the experimental instrument.

Those parameters used in the tests include the echo interval time $(0.2 \mathrm{~ms})$, waiting time $(1.5 \mathrm{~s})$, number of echoes (5000), number of scans $(64)$, ambient temperature $\left(27^{\circ} \mathrm{C}\right)$, number of iterations $(10000)$, and the results of the signal-to-noise ratio (SNR, 80). The Carr-Purcell-Meiboom-Gill (CPMG) sequence algorithm was used to measure the $T_{2}$ spectrum.

\subsection{Experimental Methods}

\subsubsection{Pore Characterization}

To characterize the pore-fracture system of coal samples, the pore types have been divided into adsorption pores (with a diameter smaller than $10^{2} \mathrm{~nm}$ ), seepage pores (with a diameter between $10^{2}$ and $10^{4} \mathrm{~nm}$ ), and fractures (with a diameter larger than $10^{4} \mathrm{~nm}$ ). The above classification is according to the role of the pore in the migration and storage of CBM and the characteristics of the $T_{2}$ spectrum for different pore sizes.(37-39) The following designed tests are the focus for these three types of pores:

A total of 7-10 g of the two coal samples was selected and crushed into $2-4 \mathrm{~mm}$ blocks, respectively. An Autopore IV9500 mercury intrusion instrument is used for the high-pressure mercury intrusion (HPMI) porosimetry test. Each coal sample was tested for 120 pressure points; the stability time for each point was $5 \mathrm{~s}$; and the working pressure of the mercury intrusion test was $0.124-270.79 \mathrm{MPa}$. For reliability of the results, data in which the pore diameter is above $10 \mu \mathrm{m}$ were deleted. The test results can be used to analyze the characteristics of seepage pores.

The remaining samples were further ground to 40-60 mesh to perform a low-temperature liquid nitrogen gas adsorption ( $\mathrm{LTN}_{2} \mathrm{GA}$ ) test. Pore surface morphology of adsorption pores was measured using the Trostar II3020 specific surface area analyzer and pore size distribution analyzer, and the testing temperature is $77 \mathrm{~K}$. The distribution and specific surface area of pores (pore diameter between 2 and $100 \mathrm{~nm}$ ) were determined by the Barrett-Joyner-Halenda (BJH) model.(40,41) Then, a low-pressure carbon dioxide gas adsorption ( $\left.\mathrm{LPCO}_{2} \mathrm{GA}\right)$ test was carried out at $273.15 \mathrm{~K}$ using the 
Micromeritics ASAP 2020 specific surface area and pore analyzer. The distribution of micropores (pore diameter smaller than $2 \mathrm{~nm}$ ) was determined by the density functional theory (DFT) model. $(42,43)$

\subsubsection{Physical Simulation of Gas and Water Migration}

Cylinders with a diameter of $25 \mathrm{~mm}$ and length of $30 \mathrm{~mm}$ was prepared from coal samples for NMR analyses. Two samples (SJ1 and SJ2) were drilled from coal block SJ, and one sample (XZ1) was drilled from coal block XZ. Samples SJ1 and XZ1 were used to conduct the simulation of water injection and displacement, and sample SJ2 was used to conduct the simulation of adsorption and desorption.

In the condition that the holder of the instrument is empty, the temperature of the instrument was set to $25.0^{\circ} \mathrm{C}$ and the $T_{2}$ spectrum of the empty holder cavity was measured. Before the measurement, the samples were placed in a drying oven at $105^{\circ} \mathrm{C}$ for approximately $6 \mathrm{~h}$. After finishing it, the sample was put into the holder and then initial confining pressure of $11 \mathrm{MPa}$ was set by injecting fluorine oil into the instrument. After the confining pressure stabilizes, the $T_{2}$ spectrum of the dry coal sample was measured in the same conditions as the above test.

\subsubsection{Simulation of Water Injection and Drainage}

The first step is that water injection is carried out using the apparatus shown in Figure 2. In this step, the gas (nitrogen and methane) injection system was closed and the water injection system was opened. The injecting water pressure increased from 0.6 to 6 or $8 \mathrm{MPa}$ by instantly adjusting the inlet pressure to the corresponding value, and water flowing out at the outlet of valve 4 indicates that water has passed through the whole coal sample. During the whole process, the effective stress is maintained at $11 \mathrm{MPa}$ by setting the value of confining pressure when the injecting water pressure varies. Lasting for $80 \mathrm{~min}$, the water injection amount reached saturation under each water injecting pressure. Meanwhile, the corresponding $T_{2}$ spectrum was measured at 10 min intervals and was monitored continuously for approximately $80 \mathrm{~min}$ at each injecting pressure (Figure 3).

Figure 3

\section{Simulation experiment of Gas-Water migration}

Simulation on water injection and drainage

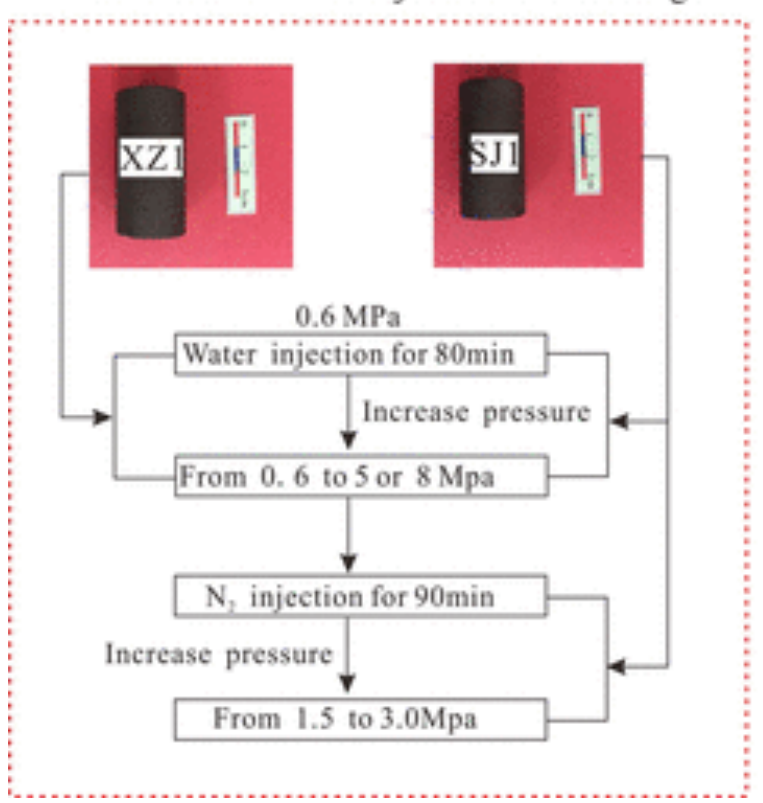

Simulation on gas adsorption and desorption

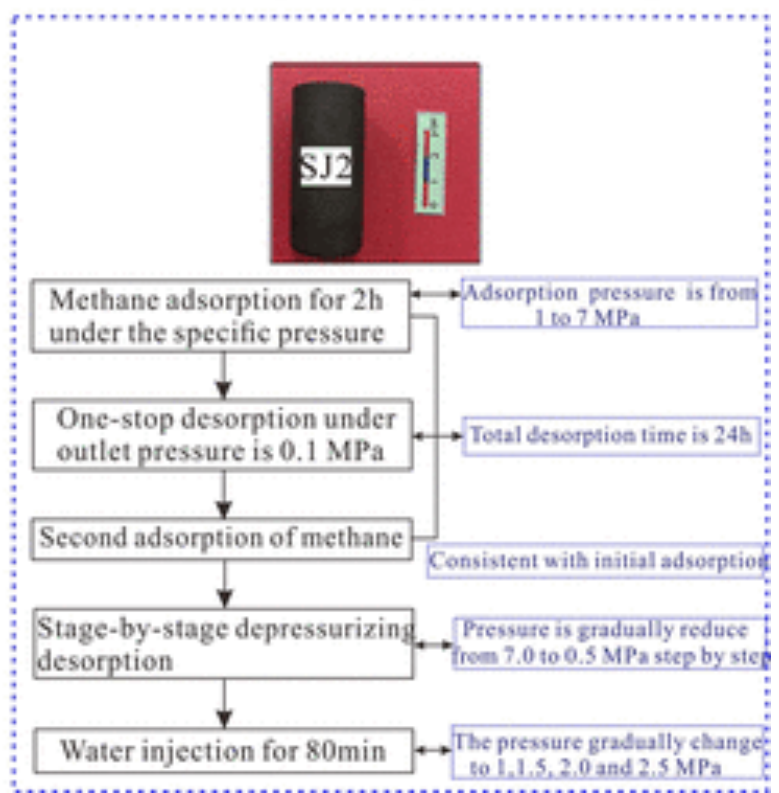

Figure 3. Process diagram of physical simulation experiments.

The second step is that the nitrogen flooding simulation continued to be conducted in the same sample after the water injection simulation had been completed. After $8 \mathrm{MPa}$ of water pressure continuously injected into the sample for $80 \mathrm{~min}$, the water injection system was closed and the nitrogen injection system was opened, whereas the rest of the operations remained the same state as the first step. The injecting nitrogen pressure increases from $1.5 \mathrm{MPa}$ by instantly adjusting the inlet 
pressure to the corresponding value, and it was set to $3.0 \mathrm{MPa}$ at the operating time of $90 \mathrm{~min}$. The $T_{2}$ spectrum is measured at 10 min intervals (Figure 3 ). In the whole process, the effective stress was maintained at $11 \mathrm{MPa}$ by setting the value of confining pressure when the injecting water pressure changes.

\subsubsection{Simulation of Methane Adsorption and Desorption}

The dried sample was used to conduct the simulation of methane adsorption and desorption. In this procedure, the water injection system was closed, the methane injection system was opened, and the vacuum pump ( $2 \mathrm{XZ}-4$ Rotary) pumped the instrument cavity vacuum for $1 \mathrm{~h}$. The whole process consists of four steps.

The first step is the simulation of methane adsorption. Methane injecting pressure was set to $1,2,3$, $4,5,6$, and $7 \mathrm{MPa}$, one after the other, by instantly setting the pressure value. The $T_{2}$ spectrum of each pressure is measured by the CPMG sequence until the spectrum becomes stable (the sample is adsorbed in each injecting pressure for $2 \mathrm{~h}$ ). In this state, the adsorption of the coal sample reaches saturation under the set pressure and the $T_{2}$ spectrum is measured at $10 \mathrm{~min}$ intervals.

The second step is the simulation of one-stop desorption by instantly reducing the outlet pressure to atmospheric pressure $(0.1 \mathrm{MPa})$. In this step, the methane injection system was closed.

The $T_{2}$ spectrum is measured at 20 min intervals, and the total desorption time is $24 \mathrm{~h}$.

The third step is the simulation of stage-by-stage depressurizing methane desorption. The one-stop desorbed sample was readsorbed to saturate the coal sample again (the measured $T_{2}$ spectrum is consistent with that of the adsorption at the first step). After adsorption saturation, the outlet of valve 4 is connected to the back-pressure valve (refer to Figure 2). The outlet pressure is reduced from 7 $\mathrm{MPa}$ to a lower value by quickly adjusting the value to $6,5,4,3,2,1$, and $0.5 \mathrm{MPa}$. The adjusting time interval is set to $4 \mathrm{~h}$, and the $T_{2}$ spectrum is measured at 10 min intervals. To ensure consistency of time between one-stop desorption and stage-by-stage depressurizing desorption, six pressure values (the same as that of step one) were set and the measurement time of each pressure point was $4 \mathrm{~h}$. The fourth step is the simulation of methane displacement by heavy water. Heavy water is used as a medium here to study the methane displacement process because it can avoid interference between $\mathrm{H}^{+}$signals of methane and water. After the coal sample is desorbed for $4 \mathrm{~h}$ at a methane pressure of $0.5 \mathrm{MPa}$, the outlet pressure valve was removed in this step and then the water injection system was opened. The rest of the simulation system remained unchanged. The water injecting pressure increases from 1 to $3 \mathrm{MPa}$ by instantly adjusting the inlet pressure to the corresponding value. The $T_{2}$ spectrum is measured at 10 min intervals. The simulation was completed when the $T_{2}$ spectrum remain unchanged (Figure 3 ).

\subsection{Data Selection and Processing}

After the original echo data series was obtained at a specific injecting pressure and time, the data are inverted using simultaneous iterative reconstruction technique (SIRT) methods in Niumaglnvert software. For this method, no user intervention is required in the data processing and complex inversion control parameters do not need to be set in advance, thereby reducing the deviation of the inversion result caused by anthropogenic factors.(44) Then, the corresponding $T_{2}$ spectrum can be obtained when the inversion process is finished. In theory, the pre-test $T_{2}$ spectrum was obtained by the superimposition $T_{2}$ spectrum of the dry coal sample and the instrument cavity (Figure 4). The $T_{2}$ spectrum were acquired by different water and gas injection experiments. Then, the net $T_{2}$ spectrum of water and gas injection amount is the difference between the pre-test $T_{2}$ spectrum and the measured $T_{2}$ spectrum. 


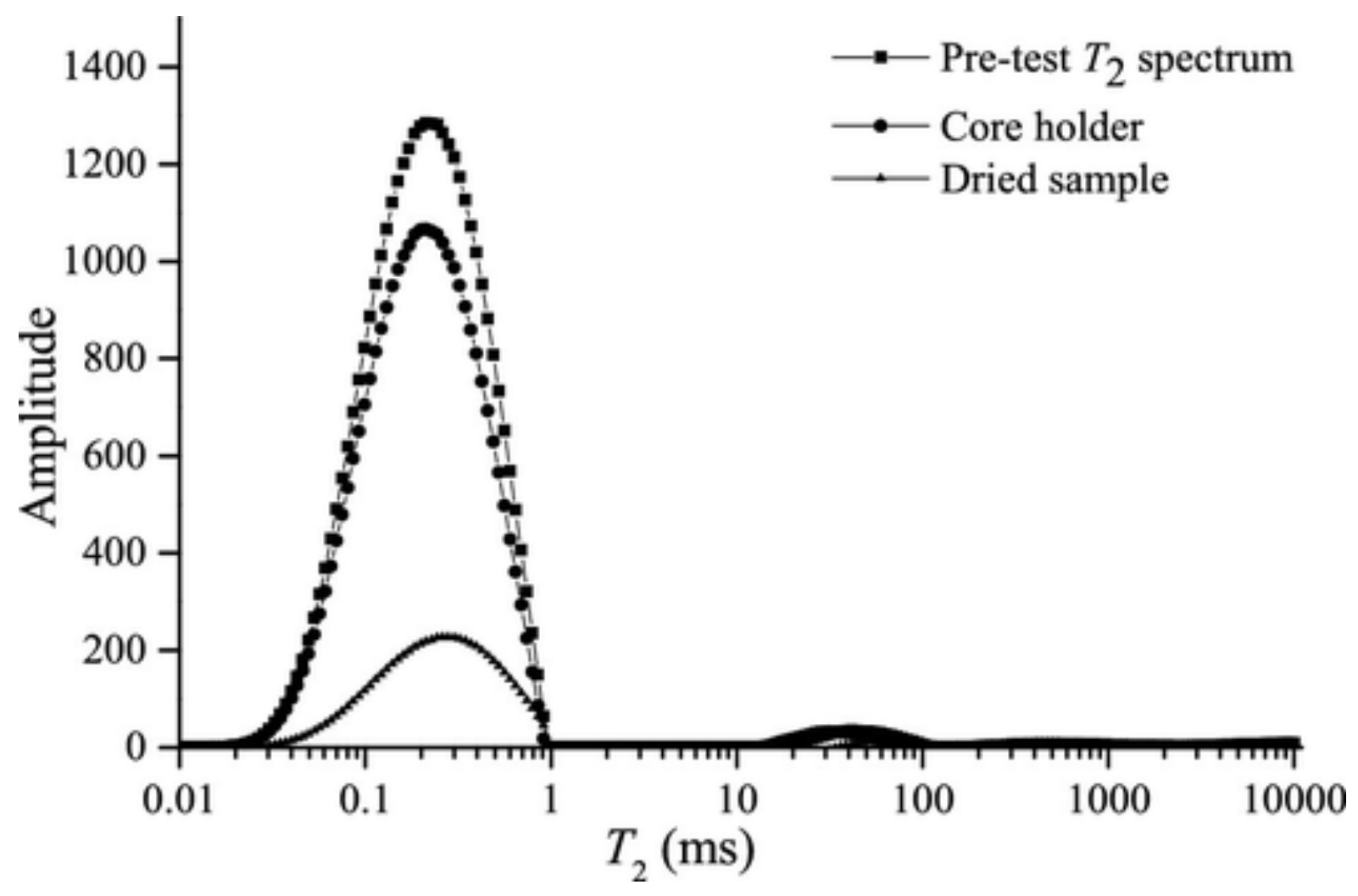

Figure 4. $T_{2}$ spectrum of dry sample SJ1.

During processing the experimental data, two methods were introduced. One is that the net $T_{2}$ spectrum of water and gas injecting amount is obtained by subtracting the pre-test $T_{2}$ spectrum from the inversed $T_{2}$ spectrum under a certain injecting pressure and time. The other is the subtraction of the pre-test data series from the measured echo data series before inversion. In comparison to the former, the $T_{2}$ spectrum obtained by the latter is relatively smoother. Therefore, the latter is used for data processing. Although the initial $T_{2}$ spectrum measured by the two methods is different, the corresponding variation of the spectrum area obtained in different $T_{2}$ values is consistent. In this paper, the dynamic process of water and gas (nitrogen and methane) injection and drainage was studied. The object of the experiment is the variation of the spectrum area under different times and pressures.

Moreover, the $T_{2}$ spectrum variations are obvious at different times under the same injecting pressure. Figure 6a is an example in which this phenomenon is explained in detail in section 3.2.1. Therefore, when studying the $T_{2}$ spectrum variation under different injecting pressures, selected data should be obtained from the saturated state under a specific pressure. On the one hand, it is a slow process for water and gases (methane and nitrogen) to saturate at a certain injecting pressure in coal reservoirs. On the other hand, the confining pressure increases accordingly with the injecting pressure variation. At the beginning of the injection, the pressure fluctuations make the measured $T_{2}$ spectrum not reflect the actual process. Therefore, the determination of the injecting time has an important effect on the results.

\section{Results and Discussion}

\subsection{Pore Type and Pore Size Distribution}

Pore type and size distributions of the two samples obtained from HPMI, LTN 2 GA, and $\mathrm{LPCO}_{2} \mathrm{GA}$ are presented in Table_2 and Figure 5. Curves of mercury injection-withdrawal and nitrogen adsorptiondesorption show that the two curves of sample SJ almost coincide and they all belong to the closed curve type, implying that mercury removal efficiency is relatively higher (Table_2). This indicates that adsorption and seepage pores in the sample are dominated by open pores. In contrast, the mercury intrusive-withdrawal curves of sample XZ separate from each other, and the latter has clear 
hysteresis loops and low desorption efficiency. This indicate that the seepage pores are mainly semiclosed pores and that there is a certain amount of ink bottle pores in the adsorption pores.

Table 2. Pore Volume of Samples SJ and XZ Based on HPMI, LTN ${ }_{2} G A$, and $L P C O_{2} G A$ Tests

\begin{tabular}{|c|c|c|c|c|c|c|c|c|}
\hline \multirow[t]{2}{*}{ Sample } & \multirow[b]{2}{*}{$R_{0, \max }$} & \multicolumn{3}{|c|}{ Adsorption pore $\left(\mathrm{cm}^{3} \cdot \mathrm{g}^{-1}\right)$} & \multicolumn{4}{|c|}{ Seepage pore $\left(\mathrm{cm}^{3} \cdot \mathrm{g}^{-1}\right)$} \\
\hline & & $\begin{array}{c}\mathrm{LP} \mathrm{CO}_{2}< \\
2 \mathrm{~nm}\end{array}$ & $\begin{array}{r}\mathrm{LT} \mathrm{N}_{2} \\
2 \sim 10^{2} \mathrm{~nm}\end{array}$ & $\begin{array}{l}\text { curve } \\
\text { type }\end{array}$ & $\begin{array}{r}\text { HPMI } \\
10^{2} \sim 10^{3} \mathrm{~nm}\end{array}$ & $\begin{array}{c}\text { HPMI } \\
10^{3} \sim 10^{4} \mathrm{~nm}\end{array}$ & $\begin{array}{l}\text { removal } \\
\text { efficiency }\end{array}$ & Curve type \\
\hline$\overline{\mathrm{SJ}}$ & 1.30 & 0.021 & 0.0020 & Closed & 0.017 & 0.011 & 72 & Closed \\
\hline $\mathrm{XZ}$ & 2.20 & 0.062 & 0.0020 & Opened & 0.030 & 0.018 & 61 & $\begin{array}{c}\text { Hysteresis } \\
\text { loop }\end{array}$ \\
\hline
\end{tabular}

Figure 5
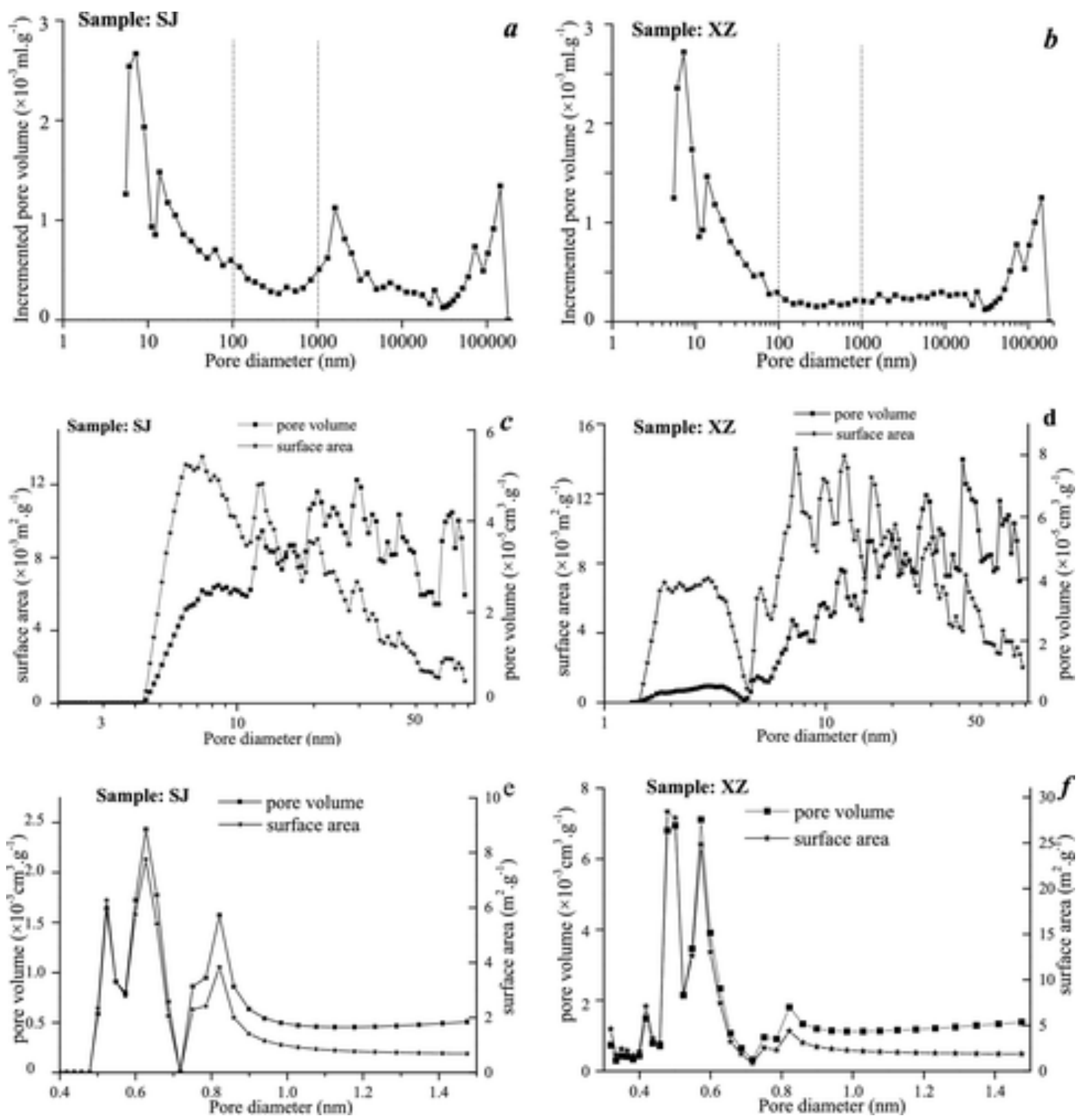

Figure 5. Pore size distribution of samples $\mathrm{SJ}$ and $X Z$ ( $a$ and $b$, pore size distributions of the seepage pore based on HPMl; $c$ and d, pore size distributions of the adsorption pore based on LTN 2 GA; e and f, pore size distributions with a diameter smaller than $2 \mathrm{~nm}$ based on $\mathrm{LPCO}_{2} \mathrm{GA}$ ). 
From Figure 5, the total pore volume (TPV) of sample XZ is larger than that of sample SJ (TPVs of sample $X Z$ and $S J$ are 0.112 and $0.051 \mathrm{~cm}^{3} \mathrm{~g}^{-1}$, respectively); the values are relatively lower. Affected by their coal rank, the percentage of pore volume of the adsorption pore (the values are 45.1 and $57.1 \%$, respectively) is nearly the same as that of the seepage pore. The pore volume of adsorption pores in both samples is provided by pores with a diameter of less than $2 \mathrm{~nm}$, and that of the seepage pores is mainly provided by the pore diameter between $10^{2}$ and $10^{3} \mathrm{~nm}$ (Figure 5 and Table_2).

\subsection{Water Injection and Drainage Characteristics of Three Types of Pores}

\subsubsection{Effect of the Injecting Pressure and Time on Water Migration}

Water injection simulations were carried out according to the setup steps, as described in subsection 2.3.2.1. The purpose of this section is to analyze the variation of the movable water in the porefracture system under the various injecting pressures and times.

At the initial injecting pressure ( $0.6 \mathrm{MPa}$ for $80 \mathrm{~min}$ ) of sample XZ1, the variation of the measured net $T_{2}$ spectrum versus injection time is presented in Figure 6 a. The $T_{2}$ spectral peaks gradually move to the left on the plot, reflecting that water gradually enters pores with relatively small diameters. The results also show three obvious peaks that are independent of each other, which also confirmed the results of the $\mathrm{LPCO}_{2} \mathrm{GA}\left(\mathrm{LTN}_{2} \mathrm{GA}\right)$ and $\mathrm{HPMI}$ test results discussed in subsection 3.1.

Figure 6
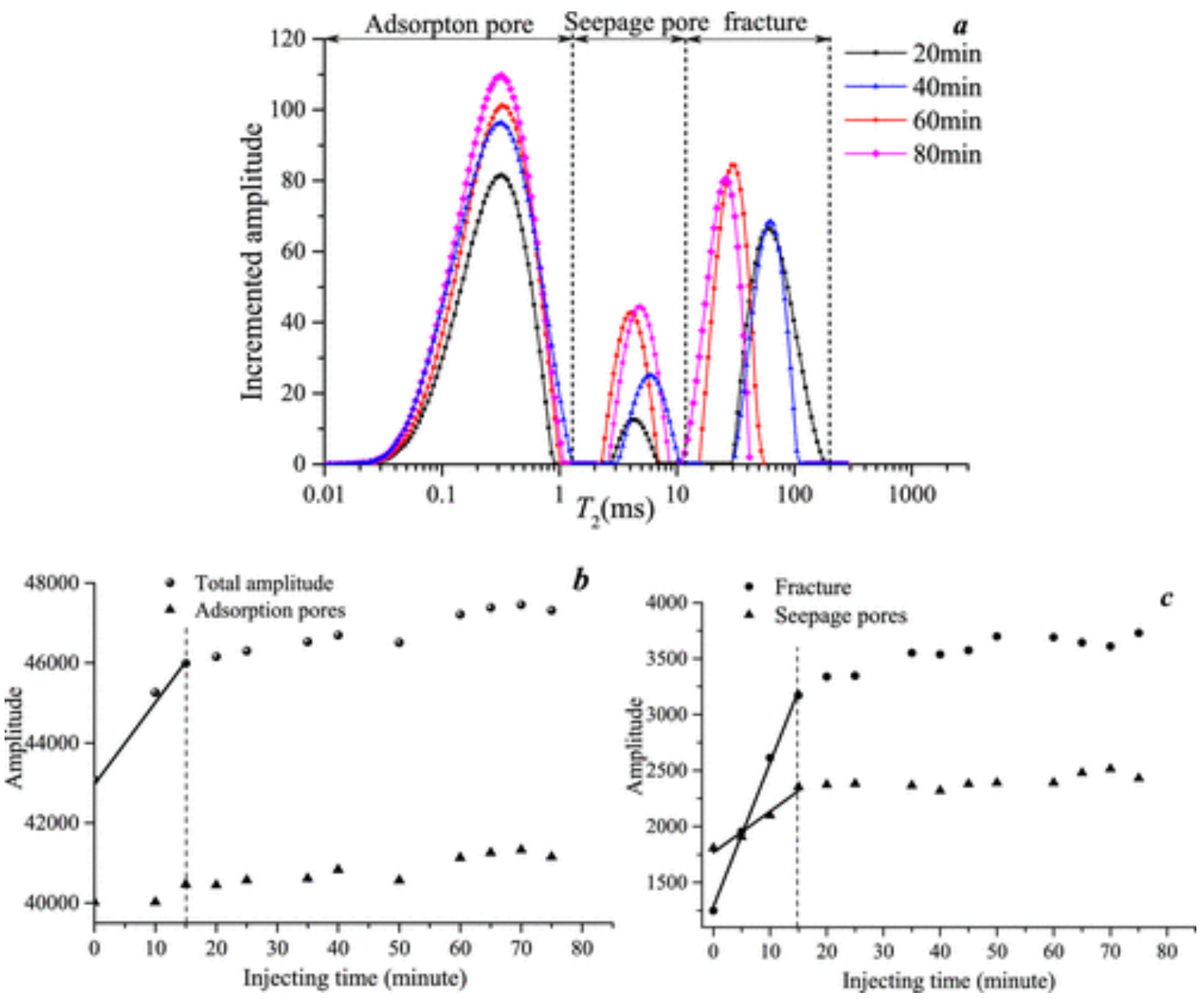

Figure 6. $T_{2}$ spectrum variation of sample $X Z 1$ under the same injecting pressure $(0.6 \mathrm{MPa})(\mathrm{a}$, net $T_{2}$ spectrum variation versus injecting time; $b$, variation of the $T_{2}$ spectral area of total pore and adsorption pores versus injecting time; and $\mathrm{c}$, variation of the $T_{2}$ spectrum area of seepage pores and fractures versus injecting time). 
Panels $b$ and $c$ of Figure 6 show that the amount of water injected into different pores increases with increasing injecting time. For a larger aperture and smaller capillary force, the $T_{2}$ spectral area of seepage pores and fractures is higher than that of adsorption pores. The injection process of water can be clearly divided into two parts. This implies that the whole injection process can be divided into two stages, that is, the rapid injection stage (before $15 \mathrm{~min}$ ) and the slow injection stage (after $15 \mathrm{~min}$ ) (Figure 6c). Because water under low injecting pressure has difficulty in overcoming the high capillary force of small pores (adsorption pores), the injection rate of adsorption pores is the lowest (Figure 6b). The injecting pressure was continuously increased from 0.6 to $6 \mathrm{MPa}$ following the preset procedure in subsection 2.3.2.1. Each pressure was maintained for $80 \mathrm{~min}$. The $T_{2}$ spectrum variations of adsorption pores, seepage pores, and fractures are presented in Figure $\underline{7}$. The results indicate that the spectral area of all pores increases with increasing injecting pressure. In addition, the total spectral area of the adsorption and seepage pores has a logarithmic relationship with the injecting pressure (Figure 7).

Figure 7
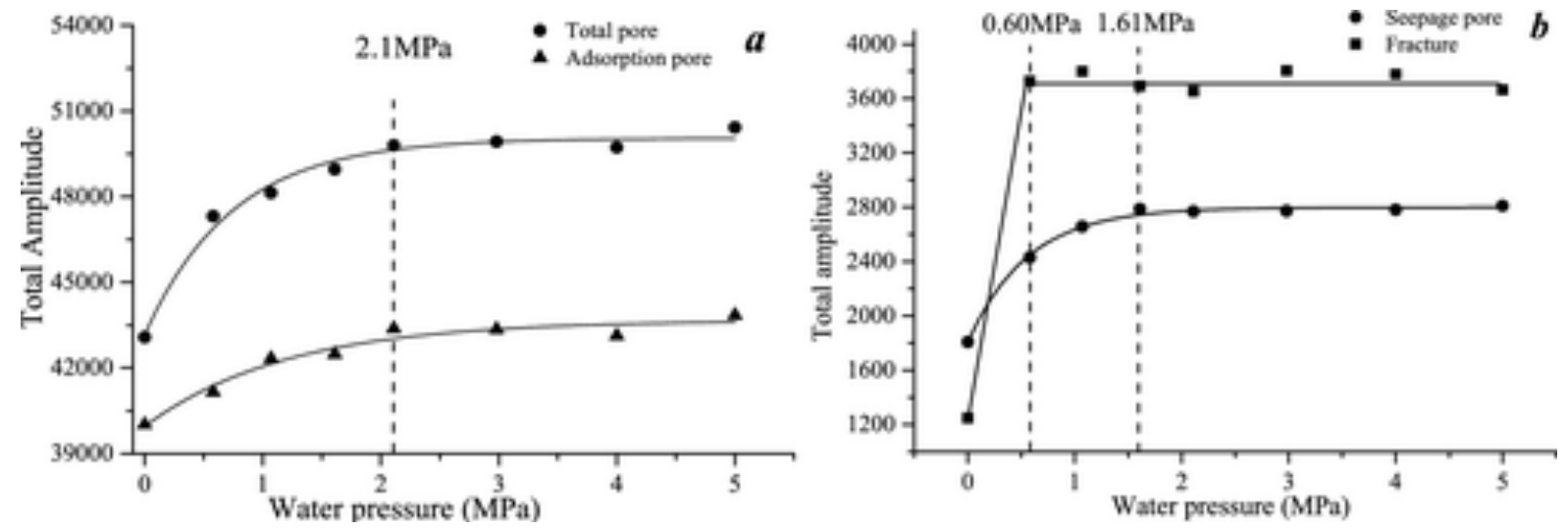

Figure 7. $T_{2}$ spectrum variation of sample $X Z 1$ under different injecting pressures (a, variation of the $T_{2}$ spectral area of total pores and adsorption pores versus injecting pressure; $b$, variation of the total $T_{2}$ spectral area of seepage pores and fractures versus injecting pressure).

The $T_{2}$ spectrum of adsorption and seepage pores was stable when injecting pressures reach 2.1 and 1.6 MPa, respectively. Different from the adsorption and seepage pores, water in the fractures rapidly reaches saturation when the injecting pressure is $0.6 \mathrm{MPa}$. Thereafter, the total $T_{2}$ spectral area of fractures remains unchanged as the pressure increases (Figure $7 \mathrm{~b}$ ). The injecting pressure corresponding to different pore saturation values $(4,3$, and $2.1 \mathrm{MPa}$ for adsorption pores, seepage pores, and fracture, respectively) indicates that water enters preferentially into fractures, followed by seepage pores and later adsorption pores (Figure $\underline{7}$ ).

\subsubsection{Displacement of Water in Various Pores by High-Pressure Nitrogen Injection}

To analyze the displacement effect of nitrogen on movable water in coal samples, water injection and displacement simulation of sample SJ1 was conducted following the way that was described in subsection 2.3.2.1. In the process of water injection simulation, there is no water that reaches the outlet when the injecting pressure is below 4.0 MPa. The injecting pressure of sample SJ1 corresponding to water breakthrough at the outlet is obviously higher than that of sample XZ (0.6 $\mathrm{MPa}$ ). Shen et al.(45) and Yuan et al.(46)found that the imbibition capacity for a given sample decreases with the increase of the sample contact angle and pore tortuosity when the pore size distribution is approximately similar. Therefore, the difference of pore tortuosity and wettability between the two samples leads to this phenomenon.

After the completion of water injection simulation, nitrogen flooding simulation was conducted. Nitrogen gas was injected into water-saturated sample SJ1 at pressures of 1.5 and $3.0 \mathrm{MPa}$ for 90 min, respectively. The results (Figure 8 ) show that the displaced water accounted for $23.4 \%$ of the total water content, indicating that nitrogen gas can effectively displace water in the sample. The process under the same displacement pressure can be divided into two parts. That is, rapid displacement in the early stage and slow displacement in the later stage (refer to Figure 8). The spectral area of adsorption pores, seepage pores, and fractures decreased significantly with 
increasing displacement pressure, indicating that the displacement effect of nitrogen under higher pressure is more significant.

Figure 8

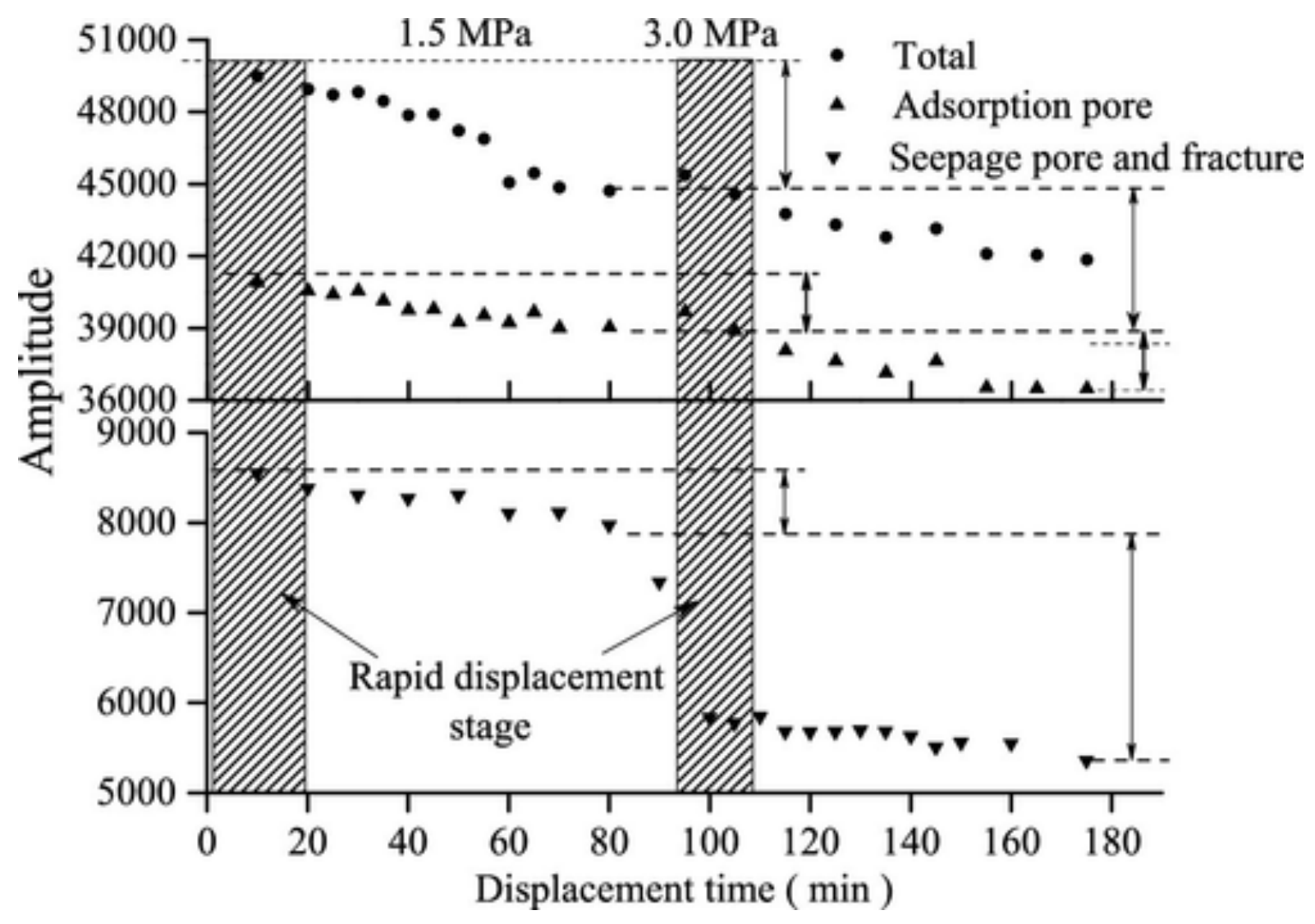

Figure 8. Spectral area of total, adsorption, and seepage pore (fracture) variation with time.

For displacement pressures of 3.0 and $1.5 \mathrm{MPa}$, the spectral area of adsorption pores, seepage pores, and fractures decreases by 10 and $60 \%$, respectively. The results indicate that seepage pores and fractures are more sensitive to the displacement pressure than adsorption pores. The reason is that water has stronger adsorption capability than nitrogen as a wetting fluid on the surface of the adsorption pore. It is difficult for nitrogen to compete with water when it enters a micropore. Therefore, it is difficult to displace water from the adsorption pore. Moreover, it is difficult for nitrogen gas to enter an adsorption pore at a lower injecting pressure as a result of the larger capillary force in it, which leads to less displaceable water in the adsorption pore.

Nitrogen injection has become one of the important displacement technologies in the field of CBM recovery.(47-49) Results of Xue et al.(33)indicate that pressure gradients required for water displacement by nitrogen in the pore-fracture system are obviously different. The results of this subsection also show that water occurring in a large pore (seepage pore and fracture) is more sensitive to displacement of nitrogen pressure. It is common knowledge that the water content in the adsorption pore plays an important role in controlling adsorption and desorption of methane. $(50,51)$ Therefore, displacement of water in small pores of a coal reservoir should be one of the research focuses of gas injection and displacement technology.

\subsection{Adsorption and Desorption of Methane in Different Types of Pores}

\subsubsection{Methane Adsorption and Migration}

Methane adsorption simulation of sample SJ2 was carried out according to the setup steps as described in subsection 2.3.2.2. The purpose of this simulation is to analyze the variation of adsorbed methane and bulk methane in the pore-fracture system under various methane injecting pressures. 
The net $T_{2}$ spectrum of the sample at different injecting pressures for the same adsorption time $(2 \mathrm{~h})$ are presented in Figure 9, showing that there are three peaks in the $T_{2}$ spectrum. According to the previous NMR calibration experiments of free methane, $(21,22,24)$ the $T_{2}$ value of smaller than $1 \mathrm{~ms}$ corresponds to adsorbed methane, which occurs dominantly in adsorption pores. The $T_{2}$ value that is between 10 and $100 \mathrm{~ms}$ corresponds to bulk methane, which is present in large pores, such as seepage pores or fractures. The $T_{2}$ value that is larger than $100 \mathrm{~ms}$ is the response of free methane, which exists in the space between the chamber and coal sample. Therefore, this will not be discussed in this paper.

Figure 9

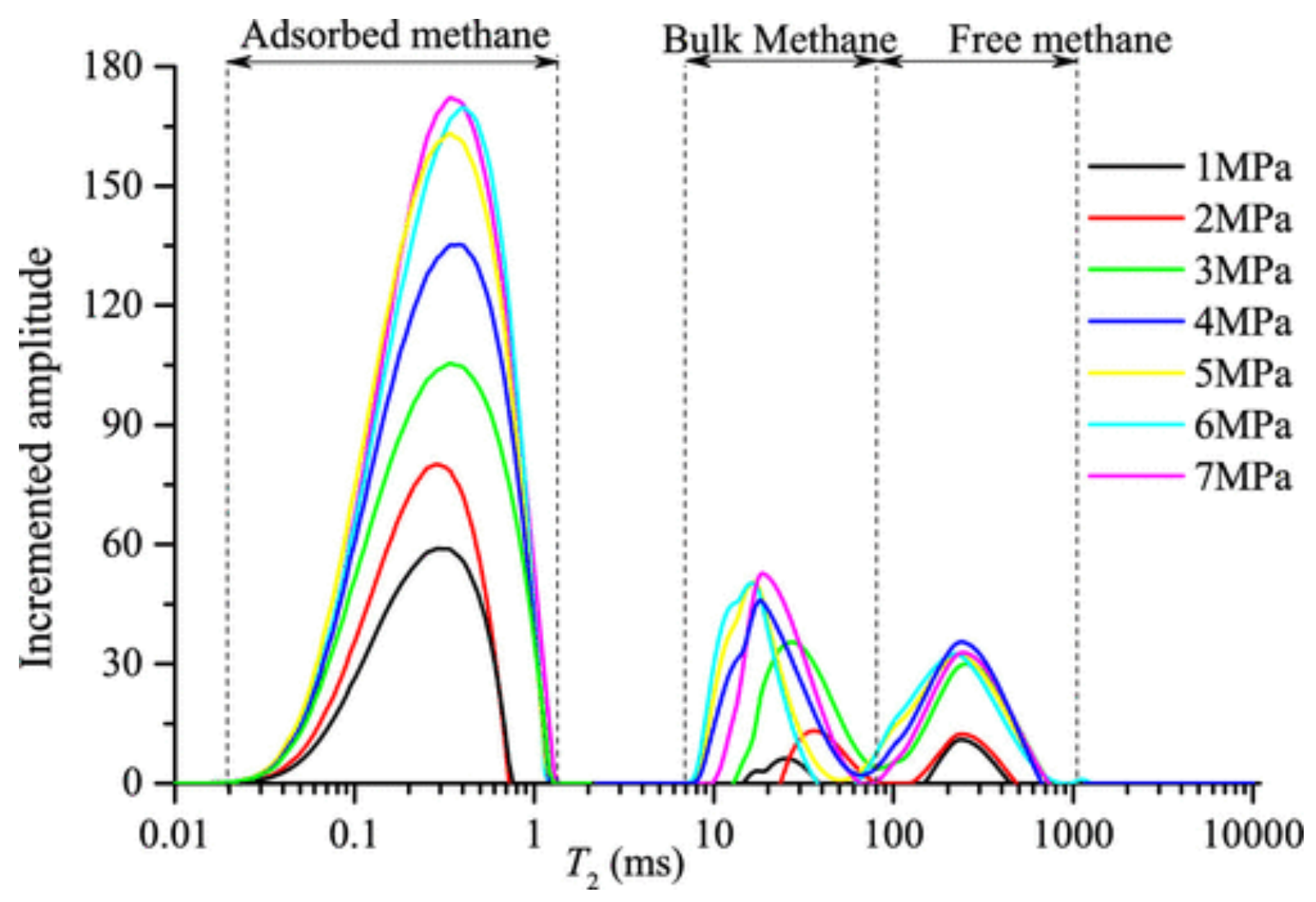

Figure 9. $T_{2}$ spectrum of sample SJ2 under different methane injecting pressures.

Figure 9 shows that the spectral area of adsorbed methane is the highest among three peaks (accounting for $80 \%$ of the total spectral area approximately), indicating that adsorbed methane is the dominant form in which methane occurs. Meanwhile, Figure 10 indicates that adsorbed methane reaches saturation at a certain lower pressure, and the linear increase of bulk methane leads to the saturation of total methane at a higher pressure. This implies that the total amount of methane measured in samples that the macropore or fracture developed cannot reliably represent the adsorption characteristics of these samples. 
Figure 10
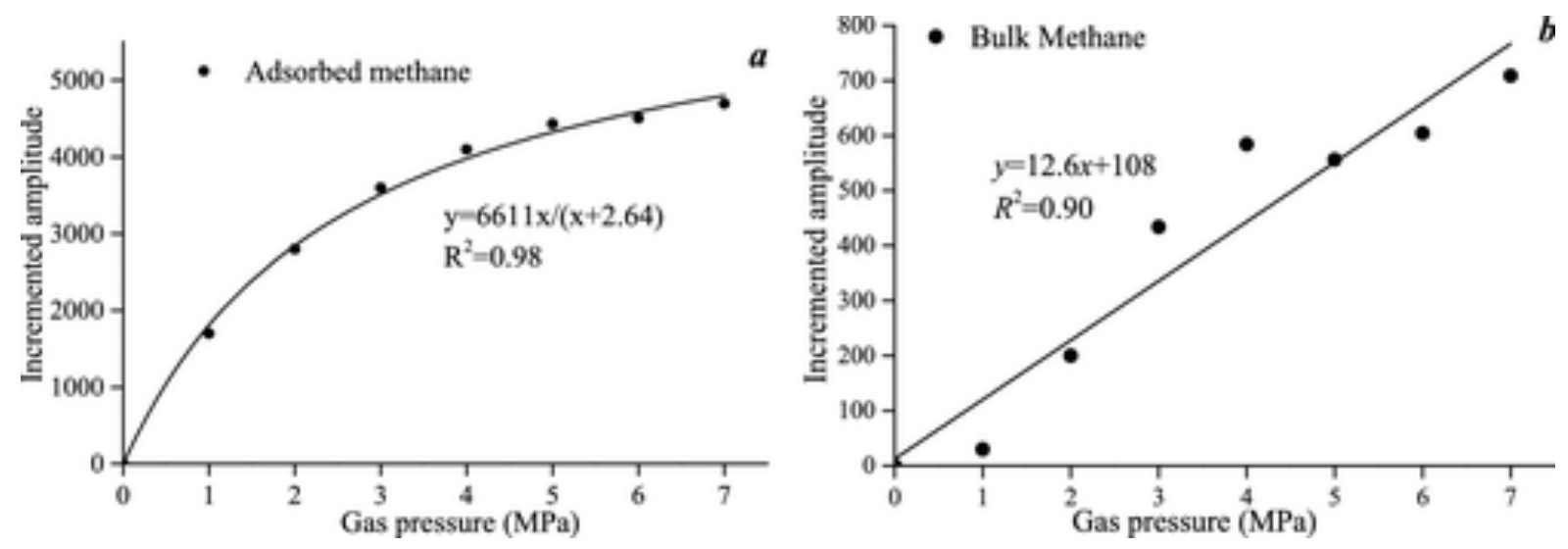

Figure 10. Variation curve of adsorbed and bulk methane at different injection gas pressures.

Figure 11 shows that variation curve of adsorbed and bulk methane under the same injection gas pressure (6 MPa). At the initial stage of adsorption (before $50 \mathrm{~min}$ ), the spectral area of adsorbed methane increases linearly with the increase of the adsorption time. Along with the continuation of the adsorption time, the adsorption rate decreases significantly and the spectral area increases slowly (after $50 \mathrm{~min}$ ). Upon an adsorption time of $400 \mathrm{~min}$, the adsorption rate of adsorbed methane tends to be stable but still not fully saturated (Figure 11a). Different from adsorbed methane, the spectral area of bulk methane increases linearly with the adsorption time. Upon an adsorption time of $250 \mathrm{~min}$, the spectral area tends to be completely at equilibrium and kept stable (Figure 11b). The difference in equilibrium time is because the migration rate of adsorbed methane controlled by the Fickian law is much lower than that of bulk methane by Darcy's law.

Figure 11
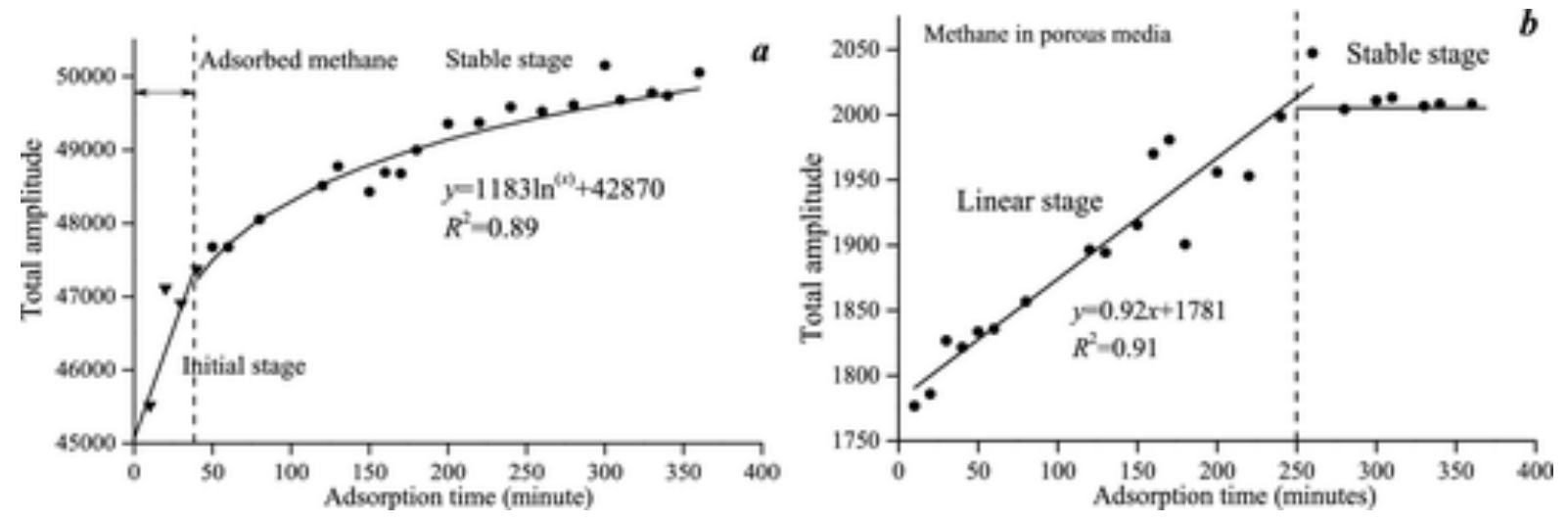

Figure 11. Variation curve of adsorbed and bulk methane under the same injecting gas pressure (6 $\mathrm{MPa})$.

Moreover, a similar behavior is observed under other methane injecting pressures.

\subsubsection{Variation of Adsorption and Bulk Methane under One-Stop Desorption}

The desorption simulation was carried out according to the setup steps in section 2.3.2.2. The purpose of this experiment is to analyze the variation of adsorbed and bulk methane with desorption time (24 $\mathrm{h}$ in total) under an outlet pressure equal to $0.1 \mathrm{MPa}$. Figure 12 shows that the spectral area of adsorbed and bulk methane decreases logarithmically with the increase of the desorption time. 
Figure 12
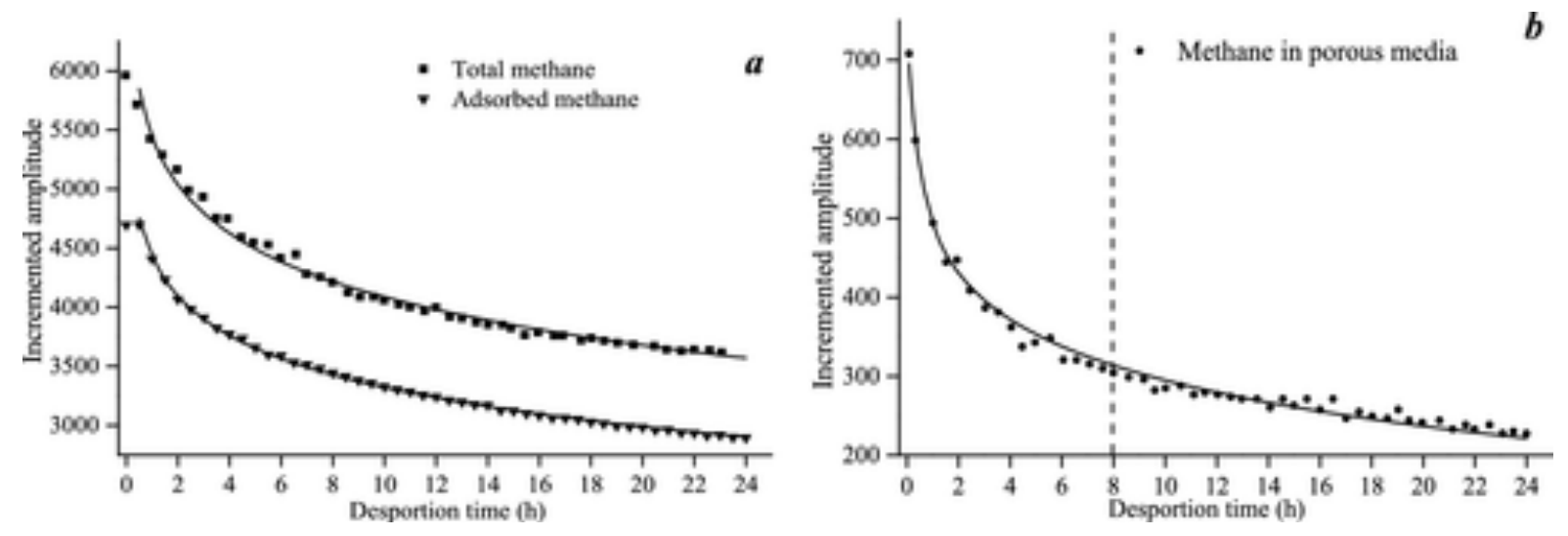

Figure 12. Variation of adsorption and bulk methane under one-stop desorption.

To achieve a quantitative description of methane desorption, a phase desorption rate $V$ is introduced to characterize methane variation per unit time. A larger value indicates a faster desorption rate $V=\frac{A_{i+1}-A_{i}}{30}$ (1)where $V$ is the desorption rate $\left(p \min ^{-1}\right.$, where $\mathrm{p}$ is a unit spectral area), $A_{i}$ is the total spectrum at the $i$ measurement, and $A_{i+1}$ is the total $T_{2}$ spectrum at the $i+1$ measurement, with both of the variables dimensionless. Each calculation time interval is $30 \mathrm{~min}$.

Figure 13 a shows that the desorption process can be divided into a rapid decline $(0-10 \mathrm{~h})$ in the early stage and a slow desorption period (10-24 h) in the later stage. The reason for this is that the average gas content and concentration gradient are higher for samples in the early stage of desorption. With progressive gas desorption, the concentration gradient decreases, which results in the decrease of the desorption rate.

Figure 13
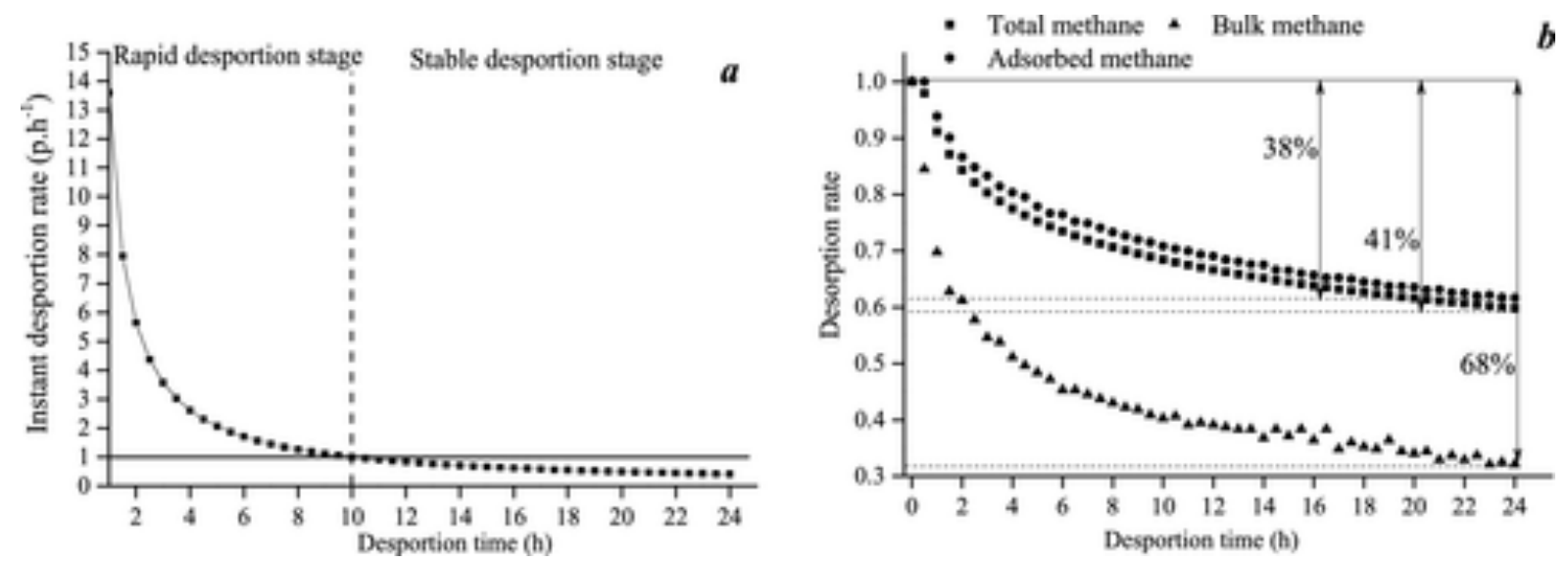

Figure 13. Desorption rate of adsorption and bulk methane under one-stop desorption.

Moreover, the variation rates of adsorbed and bulk methane versus desorption time were calculated (Figure 13b). The results show that the variation rate of bulk methane is much higher than that of adsorbed methane at the same desorption time (the variation rate is 38 and $68 \%$ for adsorption and bulk methane, respectively). Bulk methane directly migrates outside the sample driven by the pressure gradient, whereas adsorbed methane needs to be desorbed and converted into bulk methane under the same gradient and pass the adsorption pores by diffusion. Then, it will migrate out of the coal sample through the seepage pore or fracture by way of permeation. Therefore, the migration process of the latter is much more complicated than that of the former. Furthermore, the total variation rate of the sample is $41 \%$, which is dominated by adsorbed methane. The main reason is that methane in coal samples mainly occurs in the adsorbed state (Figure 9). 


\subsubsection{Variation of Adsorption and Bulk Methane under Stage-by-Stage Depressurizing Desorption}

The one-stop desorption process was carried out when the outlet pressure is atmospheric pressure $(0.1 \mathrm{MPa})$, which is different from the depressurization desorption process of CBM wells. The depressurization desorption simulation was carried out as the setup steps in section 2.3.2.2. The simulation aims to reproduce the depressurization desorption process of a coal reservoir during CBM well drainage and to describe the desorption characteristics of adsorbed and bulk methane at different depressurization rates.

Figure 14 shows that the spectral area of adsorbed and bulk methane varies when the methane pressure decreases from 7 to $0.5 \mathrm{MPa}$, which illustrates that the spectrum curves of the adsorption and desorption processes do not coincide and have clear hysteresis, while the amount of bulk methane that transforms from adsorbed methane has a linear relationship with the pressure and the two curves of different processes corresponding to bulk methane are almost the same (Figure 14c). These finding can be explained by the fact that the ink bottle pores that developed in the coal sample, lead to expansion of the coal matrix in the process of methane adsorption, resulting in the narrowing of pore channels. This will lead to an increase of the force required for gas entering or leaving the pore, so that the amount of gas adsorption is greater than that of desorption.

Figure 14
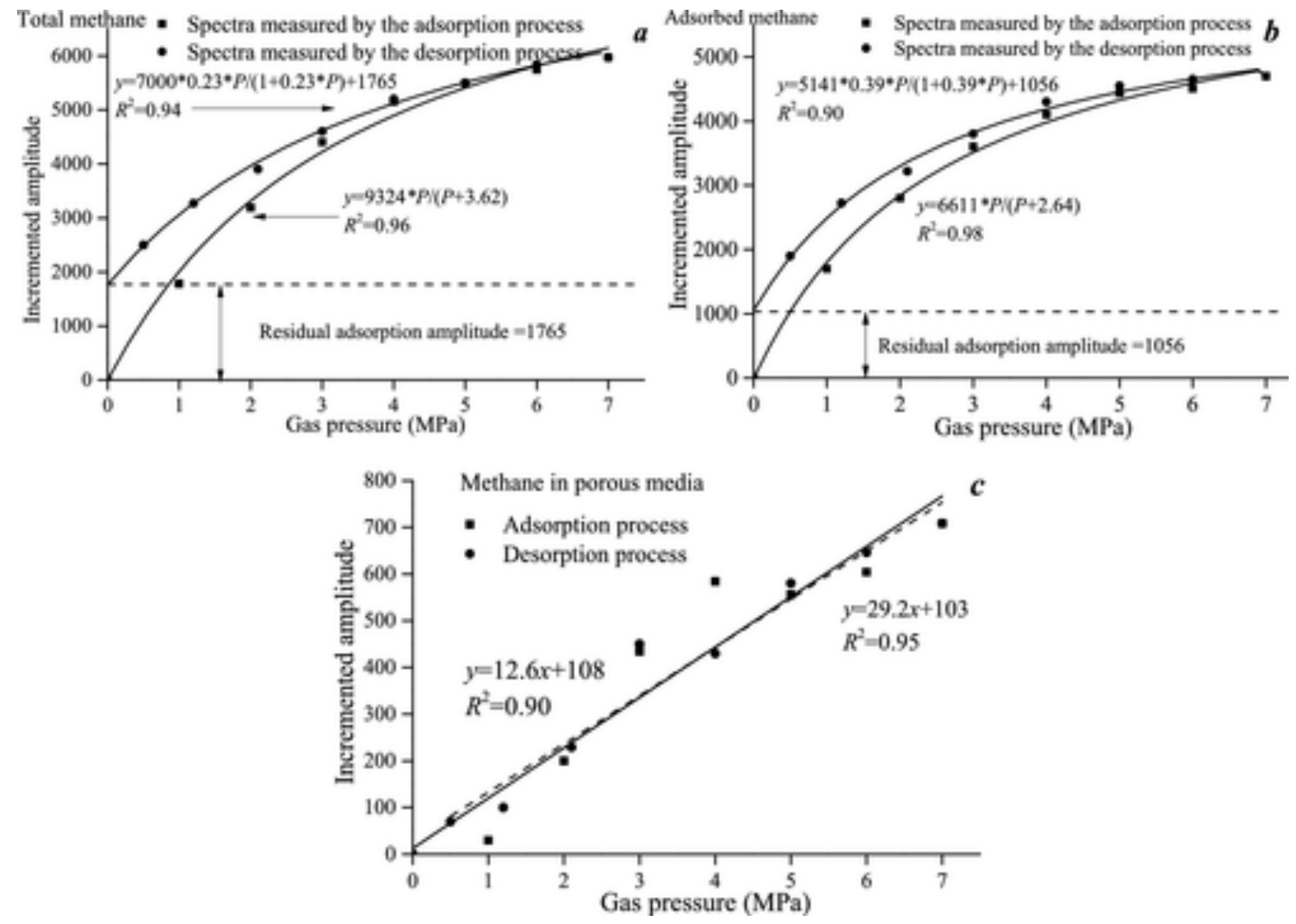

Figure 14. Spectral area of adsorbed and bulk methane variation with the decrease of the outlet pressure from 7.0 to $0.5 \mathrm{MPa}$.

These indicates that the hysteresis phenomenon in the desorption process is mainly related to adsorbed methane (Figure 14b). Different from the adsorption process, the desorption data measured by NMR technology satisfy the desorption model deduced by Ma et al.(52) and do not correlate well with the Langmuir equation. The spectral area of residual total and adsorbed methane (the value is 1765 and 1056, respectively, dimensionless) can be obtained by the deduced model. The results show that about $21 \%$ of adsorbed methane has not been desorbed in specific desorption times (Figure 14b).

The spectral area variation of adsorbed and bulk methane at different depressurization stages throughout the whole desorption process ( $24 \mathrm{~h}$ of desorption) was calculated (Table_3). For the 
adsorption pressure decreases from 7 to $4 \mathrm{MPa}$, the desorption of adsorbed methane is approximately $10 \%$ of the total amount. When the adsorption pressure decreases from 2.1 to 0.1 $\mathrm{MPa}$, the desorption amount of adsorbed methane is $59.8 \%$ of the total desorption. Within a higher adsorption pressure, the desorption amount of adsorbed methane increases slowly compared to other lower value ranges. This indicates that the depressurizing gradient has an important effect on the desorption of adsorbed methane.

Table 3. Comparison of One-Stop Desorption and Stage-by-Stage Depressurizing Desorption (with Each Pressure Interval of $4 \mathrm{~h}$ )

\begin{tabular}{|c|c|c|c|c|c|c|}
\hline \multirow[b]{2}{*}{ Desorption stage } & \multicolumn{2}{|c|}{ Adsorbed methane } & \multicolumn{2}{|c|}{ Bulk methane } & \multicolumn{2}{|c|}{ Total desorption methane } \\
\hline & $\begin{array}{l}\text { Desorption } \\
\text { amount }\end{array}$ & $\begin{array}{c}\text { Percentage of } \\
\text { desorption } \\
\text { amount } / \%\end{array}$ & $\begin{array}{l}\text { Desorption } \\
\text { amount }\end{array}$ & $\begin{array}{c}\text { Percentage of } \\
\text { desorption } \\
\text { amount } / \%\end{array}$ & $\begin{array}{l}\text { Desorption } \\
\text { amount }\end{array}$ & $\begin{array}{c}\text { Percentage of } \\
\text { desorption } \\
\text { amount } / \%\end{array}$ \\
\hline From 7.0 to $6.0 \mathrm{MPa}$ & 47 & 1.3 & 62 & 9.9 & 130 & 3.0 \\
\hline From 6.0 to $5.0 \mathrm{MPa}$ & 100 & 2.8 & 66 & 10.5 & 340 & 7.7 \\
\hline From 5.0 to $4.0 \mathrm{MPa}$ & 250 & 7.1 & 150 & 23.9 & 300 & 6.8 \\
\hline From 4.0 to $3.0 \mathrm{MPa}$ & 500 & 14.1 & 20 & 0 & 600 & 13.7 \\
\hline From 3.0 to $2.1 \mathrm{MPa}$ & 529 & 14.9 & 221 & 35.2 & 697 & 15.9 \\
\hline From 2.1 to $1.2 \mathrm{MPa}$ & 448 & 12.7 & 129 & 20.1 & 633 & 14.4 \\
\hline From 1.2 to $0.1 \mathrm{MPa}$ & 1667 & 47.1 & 80 & 12.7 & 1694 & 38.6 \\
\hline $\begin{array}{c}\text { Depressurizing } \\
\text { desorption }\end{array}$ & 3541 & 75.4 & 688 & 97.2 & 4394 & 73.6 \\
\hline One-stop desorption & 1801 & 38.0 & 480 & 68.2 & 2399 & 41.2 \\
\hline
\end{tabular}

The unit of desorption amount is dimensionless.

The reason is that the methane concentration of micropores in a lower adsorption pressure is smaller compared to the initial adsorption state (corresponding to the higher adsorption pressure); in this condition, the molecular distance between methane and the matrix will be larger than the equilibrium distance between them, which leads to the difficulty for methane to adsorb on the pore surface. Therefore, the conversion of adsorbed methane to free methane may increase alone with the rapid decrease of the methane concentration.

Different from adsorbed methane, the variation of bulk methane under per unit pressure drop is relatively stable, and the reduction rate of them is about $12 \%$ (Table_3).

In comparison to one-stop desorption, the variation rates of adsorbed methane, bulk methane, and total methane under stage-by-stage depressurizing desorption increased by 98,43 , and $79 \%$, respectively (Table_3). The results show that this desorption mode has a significant enhancing effect on the desorption of methane, indicating that the pressure gradient is positively correlated with the amount of methane desorbed. Therefore, it is related to the performance of CBM production wells; hence, a reasonable working system should be formulated to ensure a steady decrease of pressure difference.

\subsection{Displacement of Water on Methane Desorption}

After the above simulations, methane displacement by heavy water was conducted following the setup steps outlined in section 2.3.2.2. The goal of these experiments was to analyze the displacement effect of movable water on adsorbed and bulk methane.

Figure 15 shows the spectral area variation of adsorbed and bulk methane versus time under different displacement pressures. It can be seen from the figure that the spectral areas of adsorbed and bulk methane decreased by 43 and $95 \%$, respectively, indicating that the variation of bulk methane by injected water is more significant than that of adsorbed methane. In comparison to the variation rate of bulk methane, the desorption rate of adsorbed methane increases with the increase of the displacement pressure, indicating that it is more sensitive to the displacement pressure than bulk methane. It is interpreted that different mechanisms of water on methane in two states lead to these results. 
Figure 15
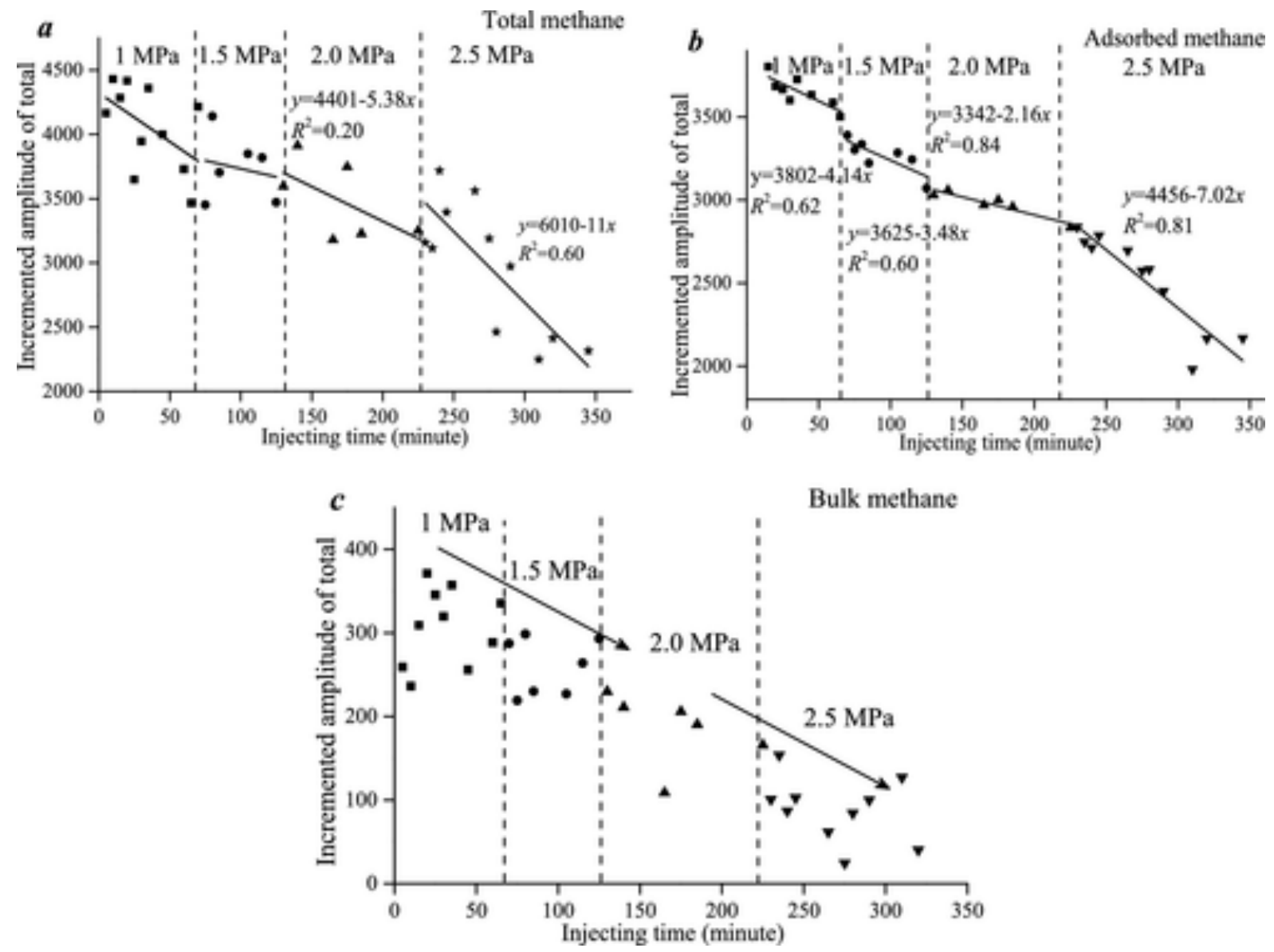

Figure 15. Variation of adsorbed and bulk methane versus different water pressures.

On one hand, liquid water displaces different states of methane mainly by way of volume replacement. Movable water enters into nanopores (adsorption pores) at a certain injecting pressure, which is subject to the preferential flow effect in the overlay model. Then, water flows by attachment to the pore surface to displace adsorbed methane from the nanopore surface (Figure 16).(19) With an increasing water injection rate (increasing water injecting pressure and time), the coal nanopore surface is gradually covered by water molecules, which displace more adsorbed methane and improve the displacement (Figure 15b). It is worth noting that increasing the water injecting pressure may lead to the increase of the internal pressure of ink bottle pores; therefore, bulk methane in the adsorption pores can be reattached to pore surfaces. However, the low injecting pressure in this simulation results in less water entering the semi-closed pores, which may cause the enhancing effect of water to weaken methane adsorption. 
Figure 16

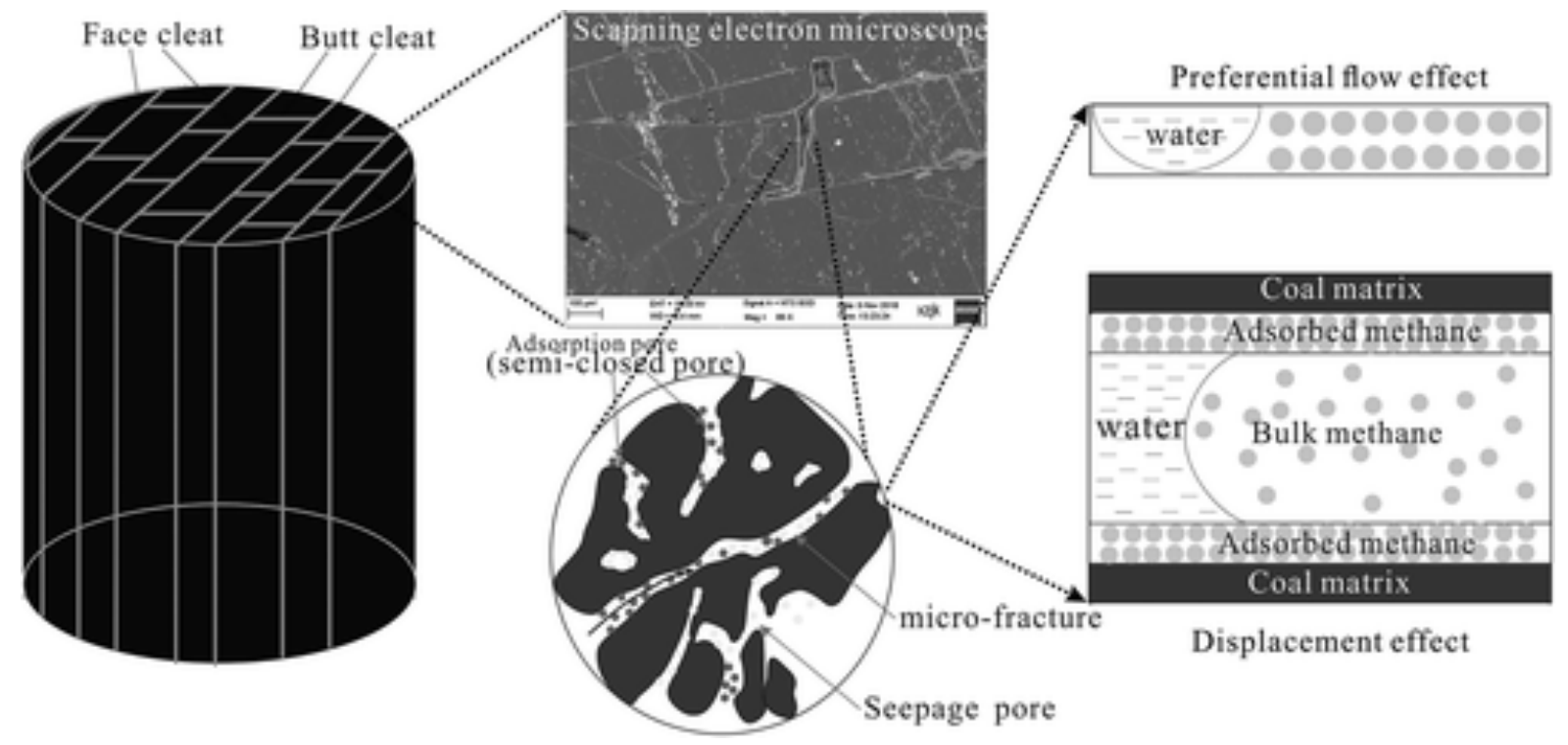

Figure 16. Schematic diagram for methane and water interaction in molded coal at the nanopore scale.

On the other hand, water primarily displaces bulk methane in seepage pores or fractures by external pressure. This is essentially the process by which water gradually fills the pore space. Bulk methane is displaced by volumetric displacement. However, the time effect is weaker than the pressure effect as a result of the shorter time, which indicates that the total displacement amount increases instantaneously with the increase of the pressure (Figure 15).

The above results show that water injected into a coal reservoir can displace adsorbed methane and bulk methane simultaneously. These results can provide a new reference for understanding gas and water interaction. Water invasive technology (including hydraulic fracturing technology) has been widely used in the prevention of gas outbursts in the coal mining industry CBM surface recovery. It is generally accepted that injected water mainly displaces bulk methane in the macropores and has a weak influence on adsorbed methane. Although the variation rate of adsorbed methane is relatively small compared to that of bulk methane, a considerable proportion of methane is desorbed. The difference in the effect between static water and dynamic water on methane adsorption and desorption needs further studies to better serve engineering applications.

\section{Conclusion}

Migration of gas and water in coal reservoirs was simulated using a modified and self-improved NMR displacement device. The injection and displacement of water, one-stop desorption, and step-by-step depressurizing desorption of the same middle-rank coal sample were conducted. Moreover, a quantitative description of the methane displacement process by water has been completed using heavy water. The conclusions are as follows: (1) For the one-stop desorption, the spectral area of adsorbed and bulk methane decreases logarithmically with the increase of the desorption time. The desorption process can be divided into the early rapid decline stage and the later slow desorption stage. Moreover, the variation rate of bulk methane is much higher than that of adsorbed methane at the same desorption time. (2) The $T_{2}$ spectrum curve of adsorption and desorption has clear hysteresis under the step-by-step depressurizing desorption, which is related to the type of pores that are adsorbed Moreover, the variation rate of bulk methane is much higher than that of adsorbed methane. In comparison to one-stop desorption, the variation rates of adsorbed methane, bulk methane, and total methane under stage-by-stage depressurizing desorption were increased by 98 , 43 , and $79 \%$, respectively. Therefore, a reasonable working system should be formulated to ensure a steady decrease of the pressure difference. (3) Nitrogen mainly displaces water in the seepage pore and fracture. The sensitivity of a large pore to displacement pressure is stronger than that of a small pore, i.e., adsorption pore. In the process of methane displacement by water, the variation rate of bulk methane is much higher than that of adsorbed methane, but the variation rate of adsorbed methane is 
more sensitive to injecting water pressure than that of bulk methane. These finding are caused by the relatively strong interaction between the coal matrix and water. It is difficult for nitrogen, methane, and other gases to form competitive adsorption with water.

\section{Acknowledgements}

This research was supported by Outstanding Innovation Scholarship for Doctoral Candidate of CUMT (2019YCBS002). The authors are grateful to anonymous reviewers for their insightful and valuable comments.

\section{References}

1. Bustin, R. M.; Clarkson, C. Geological controls on coal bed methane reservoir capacity and gas content. Int. J. Coal Geol. 1998, 38, 3-26, DOI: 10.1016/S0166-5162(98)00030-5

2. Clarkson, C.; Bustin, R. The effect of pore structure and gas pressure upon the transport properties of coal: A laboratory and modeling study. 1. Isotherms and pore volume distributions. Fuel 1999, 78 (11), 1333- 1344, DOI: 10.1016/S0016-2361(99)00055-1

3. Ayers, W. B., Jr. Coalbed gas systems, resources, and production and a review of contrasting cases from the San Juan and powder River Basins. AAPG

Bull. 2002, 86 (11), 1853- 1890, DOI: 10.1306/61EEDDAA-173E-11D7-8645000102C1865D

4. Moore, T. A. Coalbed methane: A review. Int. J. Coal Geol. 2012, 101, 36- 81, DOI: 10.1016/j.coal.2012.05.011

5. Pan, Z.; Wood, D. Coalbed methane (CBM) exploration, reservoir characterisation, production, and modelling: A collection of published research (2009-2015). J. Nat. Gas Sci.

Eng. 2015, 26, 1472- 1484, DOI: 10.1016/j.jngse.2015.07.049

6. Qin, Y.; Moore, T. A.; Shen, J.; Yang, Z.; Shen, Y.; Wang, G. Resources and geology of coalbed methane in China: A review. Int. Geol. Rev. 2018, 60 (5-6), 777-812, DOI: 10.1080/00206814.2017.1408034

7. Hildenbrand, A.; Krooss, B.; Busch, A.; Gaschnitz, R. Evolution of methane sorption capacity of coal seams as a function of burial history-a case study from the Campine Basin, NE Belgium. Int. J. Coal Geol. 2006, 66 (3), 179- 203, DOI: 10.1016/j.coal.2005.07.006

8. Pan, J.; Hou, Q.; Ju, Y.; Bai, H.; Zhao, Y. Coalbed methane sorption related to coal deformation structures at different temperatures and pressures. Fuel 2012, 102, 760-765, DOI: 10.1016/j.fuel.2012.07.023

9. Huang, L.; Ning, Z.; Wang, Q.; Zhang, W.; Cheng, Z.; Wu, X.; Qin, H. Effect of organic type and moisture on $\mathrm{CO}_{2} / \mathrm{CH}_{4}$ competitive adsorption in kerogen with implications for $\mathrm{CO}_{2}$ sequestration and enhanced $\mathrm{CH}_{4}$ recovery. Appl. Energy 2018, 210, 28-43, DOI: 10.1016/j.apenergy.2017.10.122

10. Zhou, S.; Liu, D.; Cai, Y.; Karpyn, Z.; Yao, Y. Comparative analysis of nanopore structure and its effect on methane adsorption capacity of Southern Junggar coalfield coals by gas adsorption and FIB-SEM tomography. Microporous Mesoporous Mater. 2018, 272, 117-128, DOI: 10.1016/j.micromeso.2018.06.027

11. Xie, J.; Liang, Y.; Zou, Q.; Wang, Z.; Li, X. Prediction Model for Isothermal Adsorption Curves Based on Adsorption Potential Theory and Adsorption Behaviors of Methane on Granular Coal. Energy Fuels 2019, 33 (3), 1910-1921, DOI: 10.1021/acs.energyfuels.8b03946

12. Mosher, K.; He, J.; Liu, Y.; Rupp, E.; Wilcox, J. Molecular simulation of methane adsorption in micro- and mesoporous carbons with applications to coal and gas shale systems. Int. J. Coal Geol. 2013, 109-110, 36- 44, DOI: 10.1016/j.coal.2013.01.001

13. Gensterblum, Y.; Busch, A.; Krooss, B. Molecular concept and experimental evidence of competitive adsorption of $\mathrm{H}_{2} \mathrm{O}, \mathrm{CO}_{2}$ and $\mathrm{CH}_{4}$ on organic material. Fuel 2014, 115, 581- 588, DOI: 10.1016/j.fuel.2013.07.014

14. You, J.; Tian, L.; Zhang, C.; Yao, H.; Dou, W.; Fan, B.; Hu, S. Adsorption behavior of carbon dioxide and methane in bituminous coal: A molecular simulation study. Chin. J. Chem. Eng.2016, 24 (9), 1275-1282, DOI: 10.1016/j.cjche.2016.05.008

15. Joubert, J.; Grein, C.; Bienstock, D. Effect of moisture on the methane capacity of American coals. Fuel 1974, 53, 186- 191, DOI: 10.1016/0016-2361(74)90009-X

16. Crosdale, P.; Moore, T.; Mares, T. Influence of moisture content and temperature on methane adsorption isotherm analysis for coals from a low-rank, biogenically-sourced gas reservoir. Int. J. Coal Geol. 2008, 76 (1-2), 166- 174, DOI: 10.1016/j.coal.2008.04.004 
17. Pan, Z.; Connell, L.; Camilleri, M.; Connelly, L. Effects of matrix moisture on gas diffusion and flow in coal. Fuel 2010, 89 (11), 3207-3217, DOI: 10.1016/j.fuel.2010.05.038

18. Kim, H.; Shi, Y.; He, J.; Lee, $\mathrm{H}$.; Lee, C. Adsorption characteristics of $\mathrm{CO}_{2}$ and $\mathrm{CH}_{4}$ on dry and wet coal from subcritical to supercritical conditions. Chem. Eng. J. 2011, 171 (1), 45- 53, DOI: 10.1016/j.cej.2011.03.035

19. Wang, Z.; Su, W.; Tang, X.; Wu, J. Influence of water invasion on methane adsorption behavior in coal. Int. J. Coal Geol. 2018, 197, 74- 83, DOI: 10.1016/j.coal.2018.08.004

20. Wu, J.; Yu, J.; Wang, Z.; Fu, X.; Su, W. Experimental investigation on spontaneous imbibition of water in coal: Implications for methane desorption and diffusion. Fuel 2018, 231, 427- 437, DOI: 10.1016/j.fuel.2018.05.105

21. Yao, Y.; Liu, D.; Xie, S. Quantitative characterization of methane adsorption on coal using a lowfield NMR relaxation method. Int. J. Coal Geol. 2014, 131, 32- 40, DOI: 10.1016/j.coal.2014.06.001

22. Liu, J.; Yao, Y.; Liu, D.; Elsworth, D. Experimental evaluation of $\mathrm{CO}_{2}$ enhanced recovery of adsorbed-gas from shale. Int. J. Coal Geol. 2017, 179, 211-218, DOI: 10.1016/j.coal.2017.06.006

23. Liu, Y.; Wang, C. Determination of the Absolute Adsorption Isotherms of $\mathrm{CH}_{4}$ on Shale with LowField Nuclear Magnetic Resonance. Energy Fuels 2018, 32 (2), 1406-1415, DOI: 10.1021/acs.energyfuels.7b03428

24. Yao, Y.; Liu, J.; Liu, D.; Chen, J.; Pan, Z. A new application of NMR in characterization of multiphase methane and adsorption capacity of shale. Int. J. Coal

Geol. 2019, 201, 76- 85, DOI: 10.1016/j.coal.2018.11.018

25. Du, X.; Gu, M.; Liu, Z.; Zhao, Y.; Sun, F.; Wu, T. Enhanced Shale Gas Recovery by the Injections of $\mathrm{CO}_{2}, \mathrm{~N}_{2}$, and $\mathrm{CO}_{2} / \mathrm{N}_{2}$ Mixture Gases. Energy Fuels 2019, 33 (6), 5091-5101, DOI: 10.1021/acs.energyfuels.9b00822

26. Li, L.; Li, C.; Kang, T. Adsorption/Desorption Behavior of $\mathrm{CH}_{4}$ on Shale during the $\mathrm{CO}_{2}$ Huff-andPuff Process. Energy Fuels 2019, 33 (6), 5147- 5152, DOI: 10.1021/acs.energyfuels.9b00920

27. Zhao, G.; Wang, C. Influence of $\mathrm{CO}_{2}$ on the adsorption of $\mathrm{CH}_{4}$ on shale using low-field nuclear magnetic resonance technique. Fuel 2019, 238, 51- 58, DOI: 10.1016/j.fuel.2018.10.092

28. Liu, X.; Wu, C. Simulation of dynamic changes of methane state based on NMR during coalbed methane output. Fuel 2017, 194, 188-194, DOI: 10.1016/j.fuel.2017.01.011

29. Li, S.; Tang, D.; Pan, Z.; Xu, H.; Huang, W. Characterization of the stress sensitivity of pores for different rank coals by nuclear magnetic resonance. Fuel 2013, 111, 746-54, DOI: 10.1016/j.fuel.2013.05.003

30. Zhang, J.; Wei, C.; Ju, W.; Yan, G.; Lu, G.; Hou, X.; Kai, Z. Stress sensitivity characterization and heterogeneous variation of the pore-fracture system in middle-high rank coals reservoir based on NMR experiments. Fuel 2019, 238, 331-344, DOI: 10.1016/j.fuel.2018.10.127

31. Chen, S.; Tang, D.; Tao, S.; Ji, X.; Xu, H. Fractal analysis of the dynamic variation in pore-fracture systems under the action of stress using a low-field NMR relaxation method: An experimental study of coals from western Guizhou in China. J. Pet. Sci. Eng. 2019, 173, 617-629, DOI: 10.1016/j.petrol.2018.10.046

32. Liu, X.; Wu, C.; Zhao, K. Feasibility and Applicability Analysis of $\mathrm{CO}_{2}-\mathrm{ECBM}$ Technology Based on $\mathrm{CO}_{2}-\mathrm{H}_{2} \mathrm{O}-$ Coal Interactions. Energy Fuels 2017, 31 (9), 9268-9274, DOI: 10.1021/acs.energyfuels.7b01663

33. Xue, D. J.; Zhou, H. W.; Liu, Y. T.; Deng, L. S.; Zhang, L. Study of Drainage and Percolation of Nitrogen-Water Flooding in Tight Coal by NMR Imaging. Rock Mech. Rock Eng. 2018, 51, 3421-3437, DOI: 10.1007/s00603-018-1473-6

34. Sun, X.; Yao, Y.; Liu, D.; Zhou, Y. Investigations of $\mathrm{CO}_{2}$-water wettability of coal: NMR relaxation method. Int. J. Coal Geol. 2018, 188, 38- 50, DOI: 10.1016/j.coal.2018.01.015

35. Li, X.; Fu, X.; Ranjith, P.; Fang, Y. Retained water content after nitrogen driving water on flooding saturated high volatile bituminous coal using low-field nuclear magnetic resonance. J. Nat. Gas Sci. Eng. 2018, 57, 189- 202, DOI: 10.1016/j.jngse.2018.07.010

36. Gui, B.; Wang, C. Structural characteristics of coalbed methane in East Yunnan and West Guizhou area. Yunnan Geol. 2000, 19 (4), 321- 351, (in Chinese with an English abstract)

37. Yao, Y.; Liu, D.; Tang, D.; Tang, S.; Huang, W. Fractal characterization of adsorption-pores of coals from North China: An investigation on $\mathrm{CH} 4$ adsorption capacity of coals. Int. J. Coal Geol.2008, 73 (1), 27-42, DOI: 10.1016/j.coal.2007.07.003

38. Yao, Y.; Liu, D.; Tang, D.; Tang, S.; Huang, W.; Liu, Z.; Che, Y. Fractal characterization of seepage-pores of coals from China: An investigation on permeability of coals. Comput. Geosci.2009, 35 (6), 1159-1166, DOI: 10.1016/j.cageo.2008.09.005 
39. Yao, Y.; Liu, D.; Che, Y.; Tang, D.; Tang, S.; Huang, W. Petrophysical Characterization of coals by Low-Field Nuclear Magnetic Resonance (NMR). Fuel 2010, 89 (7), 1371-1380, DOI: 10.1016/j.fuel.2009.11.005

40. Barrett, E. P.; Joyner, L. G.; Halenda, P. P. The determination of pore volume and area distributions in porous substances. I. Computations from nitrogen isotherms. J. Am. Chem. Soc. 1951, 73, 373-80, DOI: 10.1021/ja01145a126

41. Zhao, J.; Xu, H.; Tang, D.; Mathews, J. P.; Li, S.; Tao, S. A comparative evaluation of coal specific surface area by $\mathrm{CO}_{2}$ and $\mathrm{N}_{2}$ adsorption and its influence on $\mathrm{CH}_{4}$ adsorption capacity at different pore size. Fuel 2016, 183, 420-431, DOI: 10.1016/j.fuel.2016.06.076

42. Seaton, N. A.; Walton, J. P. R. B.; Quirke, N. A new analysis method for the determination of the pore size distribution of porous carbons from nitrogen adsorption measurements. Carbon1989, 27 (6), 853- 861, DOI: 10.1016/0008-6223(89)90035-3

43. Landers, J.; Gor, G.; Neimark, A. Density functional theory methods for characterization of porous materials. Colloids Surf., A 2013, 437, 3- 32, DOI: 10.1016/j.colsurfa.2013.01.007

44. Wang, Z.; Xiao, L.; Liu, T. New method and application of multi-index inversion for NMR relaxation signals. Sci. China, Ser. G: Phys., Mech. Astron. 2003, 33 (4), 323- 332

45. Shen, J.; Zhao, J.; Qin, Y.; Shen, Y.; Wang, G. Water imbibition and drainage of high rank coals in Qinshui Basin, China. Fuel 2018, 211, 48- 59, DOI: 10.1016/j.fuel.2017.09.039

46. Yuan, X.; Yao, Y.; Liu, D.; Pan, Z. Spontaneous imbibition in coal: Experimental and model analysis. J. Nat. Gas Sci. Eng. 2019, 67, 108-121, DOI: 10.1016/j.jngse.2019.04.016

47. Jessen, K.; Tang, G.; Kovscek, A. Laboratory and Simulation Investigation of Enhanced Coalbed Methane Recovery by Gas Injection. Transp. Porous Media 2008, 73 (2), 141-159, DOI: 10.1007/s11242-007-9165-9

48. Yang, H.; Feng, Z.; Chen, L. Analysis of replacement displacement effect and its change mechanism in simulation experiment of nitrogen injection into coal seam. J. China Coal Soc.2016, 41 (9), 2246-2250

49. Zhang, L.; Kuang, Y.; Zhang, X.; Song, Y.; Liu, Y.; Zhao, J. Analyzing the Process of Gas Production from Methane Hydrate via Nitrogen Injection. Ind. Eng. Chem.

Res. 2017, 56 (26), 7585- 7592, DOI: 10.1021/acs.iecr.7b01011

50. Joubert, J.; Grein, C.; Bienstock, D. Effect of moisture on the methane capacity of American coals. Fuel 1974, 53, 186- 191, DOI: 10.1016/0016-2361(74)90009-X

51. Crosdale, P.; Moore, T.; Mares, T. Influence of moisture content and temperature on methane adsorption isotherm analysis for coals from a low-rank, biogenically-sourced gas reservoir. Int. J. Coal Geol. 2008, 76 (1-2), 166- 174, DOI: 10.1016/j.coal.2008.04.004

52. Ma, D.; Zhang, S.; Yan, Y. Isothermal adsorption and desorption experiment of coal and experimental results accuracy fitting. J. China Coal Soc. 2011, 36 (03), 477-480, (in Chinese) 